\title{
Efficiency of small scale carbon mitigation by patch iron fertilization
}

\author{
J. L. Sarmiento ${ }^{1}$, R. D. Slater ${ }^{1}$, J. Dunne ${ }^{2}$, A. Gnanadesikan ${ }^{2}$, and M. R. Hiscock ${ }^{1}$ \\ ${ }^{1}$ Atmospheric and Oceanic Sciences Program, Princeton University, Princeton, New Jersey, USA \\ ${ }^{2}$ Geophysical Fluid Dynamics Laboratory, NOAA, Princeton, New Jersey, USA
}

Received: 20 October 2009 - Published in Biogeosciences Discuss.: 11 November 2009

Revised: 14 August 2010 - Accepted: 27 August 2010 - Published: 12 November 2010

\begin{abstract}
While nutrient depletion scenarios have long shown that the high-latitude High Nutrient Low Chlorophyll (HNLC) regions are the most effective for sequestering atmospheric carbon dioxide, recent simulations with prognostic biogeochemical models have suggested that only a fraction of the potential drawdown can be realized. We use a global ocean biogeochemical general circulation model developed at GFDL and Princeton to examine this and related issues. We fertilize two patches in the North and Equatorial Pacific, and two additional patches in the Southern Ocean HNLC region north of the biogeochemical divide and in the Ross Sea south of the biogeochemical divide. We evaluate the simulations using observations from both artificial and natural iron fertilization experiments at nearby locations. We obtain by far the greatest response to iron fertilization at the Ross Sea site, where sea ice prevents escape of sequestered $\mathrm{CO}_{2}$ during the wintertime, and the $\mathrm{CO}_{2}$ removed from the surface ocean by the biological pump is carried into the deep ocean by the circulation. As a consequence, $\mathrm{CO}_{2}$ remains sequestered on century time-scales and the efficiency of fertilization remains almost constant no matter how frequently iron is applied as long as it is confined to the growing season. The second most efficient site is in the Southern Ocean. The North Pacific site has lower initial nutrients and thus a lower efficiency. Fertilization of the Equatorial Pacific leads to an expansion of the suboxic zone and a striking increase in denitrification that causes a sharp reduction in overall surface biological export production and $\mathrm{CO}_{2}$ uptake. The impacts on the oxygen distribution and surface biological export are less prominent at other sites, but nevertheless still a source of concern. The century time scale retention of iron in this model
\end{abstract}

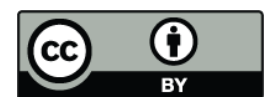

Correspondence to: J. L. Sarmiento (jls@princeton.edu) greatly increases the long-term biological response to iron addition as compared with simulations in which the added iron is rapidly scavenged from the ocean.

\section{Introduction}

The hypothesized link between surface macronutrient concentrations and the air-sea balance of $\mathrm{CO}_{2}$ has captured the interest of the scientific community ever since a reduction of surface nutrients in the Southern Ocean was first proposed independently by Knox and McElroy (1984), Sarmiento and Toggweiler (1984), and Siegenthaler and Wenk (1984), as a mechanism to explain the observed reduction of atmospheric $\mathrm{CO}_{2}$ during the ice ages. Building on these and other early box model studies by Joos et al. (1991) and Peng and Broecker (1991), there have now been a wide range of ocean general circulation model simulations examining the link between macronutrient concentrations at the surface of the ocean and the atmosphere-ocean $\mathrm{CO}_{2}$ balance (Sarmiento and Orr, 1991; Orr and Sarmiento, 1992; Kurz and MaierReimer, 1993; Archer et al., 2000; Matear and Elliott, 2004; Zeebe and Archer, 2005; Marinov et al., 2008; Gnanadesikan and Marinov, 2008). Among the major findings from these large scale macronutrient manipulation simulations are an analysis of how the air-sea $\mathrm{CO}_{2}$ balance is related to the fraction of total nutrients in the ocean that is remineralized versus preformed, and the demonstration from regional sensitivity studies that the greatest impact on the global inventory of remineralized nutrients and thus on atmospheric $\mathrm{CO}_{2}$ occurs when nutrients are depleted in the Southern Ocean High Nutrient Low Chlorophyll (HNLC) region. As regards the second point, Table 1 shows a typical result from nutrient depletion simulations using the KVHISOUTH model from

Published by Copernicus Publications on behalf of the European Geosciences Union. 
Gnanadesikan et al. (2002), which demonstrates how after 100 years of nutrient depletion, the Southern Ocean response is about 9 times the average of the other three regions in the North Atlantic, the North Pacific, and the tropical ocean.

The Southern Ocean surface nutrient reduction hypothesis as an explanation for the ice age $\mathrm{CO}_{2}$ reduction was given a further boost by the suggestion of Martin (1990) that relief of iron limitation by an increased flux of iron-bearing dust might have been the mechanism whereby the macronutrients were reduced during the ice ages. While the ideas about what caused the ice age $\mathrm{CO}_{2}$ reduction have evolved, including a more recent emphasis on physical mechanisms (e.g., Sigman and Boyle, 2000; Anderson et al., 2009), the evidence in support of the iron limitation hypothesis per se has grown over time based principally on a wide range of mesoscale iron manipulation experiments such as those described by Martin et al. (1994), Coale et al. (1996), Boyd et al. (2000, 2004), Gervais et al. (2002), Tsuda et al. (2003), Coale et al. (2004), and Hoffmann et al. (2006) (cf. reviews by de Baar et al., 2005; and Boyd et al., 2007).

The critical importance of the underlying scientific issues regarding our understanding of the linked cycles of carbon, macronutrients, and iron in the ocean have been a strong impetus for continued interest in the hypothesized link between surface nutrient concentration and atmospheric $\mathrm{CO}_{2}$, and in the iron limitation hypothesis. An additional impetus for study of these hypotheses has been the geoengineering proposal first articulated by Martin et al. (1990a) and Martin et al. (1990b) to artificially fertilize the ocean with iron as a way of removing $\mathrm{CO}_{2}$ from the atmosphere. Studies of this issue have centered primarily on determining: (1) the efficiency of the fertilization; (2) the verifiability of $\mathrm{CO}_{2}$ removal from the atmosphere; and (3) the long term environmental consequences of the fertilization (cf. Chisholm et al., 2001; and Buesseler et al., 2008). This paper is primarily about the underlying scientific issues regarding the efficiency of fertilization, but before proceeding, we note that the potential environmental consequences of extensive iron fertilization alone are sufficient to give serious pause to anyone seriously considering this as an option for $\mathrm{CO}_{2}$ removal, as discussed by Chisholm et al. (2001), Jin and Gruber (2003), Schiermeier (2003), Shepherd (2009), and Strong et al. (2009) among others. Moreover, the verifiability of $\mathrm{CO}_{2}$ sequestration as analyzed by Gnanadesikan et al. (2003) would be extremely difficult. Despite such findings, the option of carbon mitigation by patch iron fertilization continues to draw interest and thus, if for no other reason, merits serious scientific scrutiny.

The overall efficiency of iron fertilization in removing $\mathrm{CO}_{2}$ from the atmosphere is defined as the cumulative perturbation atmospheric $\mathrm{CO}_{2}$ uptake $\Delta \Phi_{\text {air-sea }}^{\mathrm{CO}_{2}}$ divided by the cumulative iron addition $\Delta \Phi_{\text {fertilization }}^{\mathrm{Fe}}$ (see Appendix A for a definition of these terms), i.e.,

$R_{\text {overall }}^{\mathrm{C}: \mathrm{Fe}}=\frac{\Delta \Phi_{\text {air-sea }}^{\mathrm{CO}_{2}}}{\Delta \Phi_{\text {fertilization }}^{\mathrm{Fe}}}$
Table 1. Results of regional iron fertilization simulations in which the effect of iron fertilization is assumed to be continuous for a period of 100 years. The total amount of carbon in the atmosphereocean system is preserved. In other words, as $\mathrm{CO}_{2}$ is removed from the atmosphere, the $\mathrm{CO}_{2}$ drops below its control value of $278 \mathrm{ppm}$, which permits $\mathrm{CO}_{2}$ to escape from the ocean in regions that are not being fertilized. These simulations provide an upper limit for how much $\mathrm{CO}_{2}$ could be removed by massive regional iron fertilization. Model drift is corrected for by subtracting a control simulation in which the total amount of carbon in the system is also fixed.

\begin{tabular}{lrr}
\hline $\begin{array}{l}\text { Region of nutrient depletion or } \\
\text { iron fertilization }\end{array}$ & \multicolumn{2}{c}{$\mathrm{CO}_{2}$ drawdown (ppm) } \\
& KVHISOUTH $^{\mathrm{a}}$ & This model $^{\mathrm{b}}$ \\
\hline Southern Ocean $\left(90^{\circ} \mathrm{S}\right.$ to $\left.30^{\circ} \mathrm{S}\right)$ & 39.0 & 35.3 \\
Tropics $\left(18^{\circ} \mathrm{S}\right.$ to $\left.18^{\circ} \mathrm{N}\right)$ & 4.6 & 9.5 \\
North Atlantic $\left(30^{\circ} \mathrm{S}-80^{\circ} \mathrm{N}\right)$ & 5.1 & 0.5 \\
North Pacific $\left(30^{\circ} \mathrm{N}\right.$ to $\left.67^{\circ} \mathrm{N}\right)$ & 3.5 & 3.2 \\
\hline GLOBAL & 52.1 & 41.8 \\
\hline
\end{tabular}

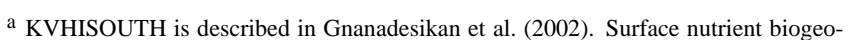
chemistry is simulated in this model by restoring model predicted surface nutrients to observations except in the region of nutrient depletion where nutrients are forced to zero. The response of this model is typical of the response of a wide range of similar such models.

${ }^{\mathrm{b}}$ In this particular simulation, where we wanted to see what would happen if iron limitation were eliminated entirely, iron fertilization was simulated by turning off iron limitation in the specified region, which essentially amounted to adding an infinite amount of iron. Note that the control scenario of the model used in this study has too high nutrients in the tropics and too low in the Southern Ocean, which contributes to enhancing its response in the tropics and muting it in the Southern Ocean relative to KVHISOUTH, where nutrients are forced towards observations in the control scenario.

It is useful to further separate the overall response function into a physical-chemical efficiency, $e_{\text {phys-chem }}$ defined as the ratio of $\Delta \Phi_{\text {air-sea }}^{\mathrm{CO}_{2}}$ to $\Delta \Phi_{\text {export }}^{\mathrm{Org} \mathrm{C} \& \mathrm{CaCO}_{3}}$, which is the cumulative perturbation export of carbon from the surface ocean that results from iron fertilization; and a biogeochemical response function $R_{\text {iron utilization }}^{\mathrm{C}: \mathrm{fe}}$ defined as the ratio of $\Delta \Phi_{\text {export }}^{\mathrm{Org} \mathrm{C}} \mathrm{CaCO}_{3}$ to $\Delta \Phi_{\text {fertilization. In equation form, we have }}^{\mathrm{Fe}}$ that:

$R_{\text {overall }}^{\mathrm{C}: \mathrm{Fe}}=e_{\text {phys-chem }} \cdot R_{\text {iron utilization }}^{\mathrm{C}: \mathrm{Fe}}$, where

$e_{\text {phys-chem }}=\frac{\Delta \Phi_{\text {air-sea }}^{\mathrm{CO}_{2}}}{\Delta \Phi_{\text {export }}^{\mathrm{Org} \mathrm{C} \mathrm{CaCO}_{3}}}$, and

$R_{\text {iron utilization }}^{\mathrm{C}: \mathrm{Fe}}=\frac{\Delta \Phi_{\text {export }}^{\mathrm{Org} \mathrm{C} \mathrm{CaCO}_{3}}}{\Delta \Phi_{\text {fertilization }}^{\mathrm{Fe}}}$

(cf. Jin et al., 2008). The mesoscale iron enrichment experiments referred to earlier have shown that the drawdown in surface dissolved inorganic carbon (DIC) that results from a given iron addition occurs at an average ratio of $R_{\mathrm{DIC}}^{\mathrm{C}: \mathrm{Fe}}$ drawdown $=5600 \mathrm{molC}$ to mol Fe added (de Baar et al., 2005). This is considerably smaller than the intracellular C:Fe ratios of $\sim 20000$ to 500000 typically observed in laboratory experiments with oceanic phytoplankton as summarized by Fung et al. (2000) and Sunda (2001), or than the mean C:Fe ratio of 200000 proposed by Johnson et 
al. (1997), which are the values typically used in estimating iron demand in geoengineering proposals for iron fertilization. This suggests that most of the iron that is being added to the ocean is not being utilized by phytoplankton, at least on the time-scale of the observations. Results from the iron manipulation experiments thus imply that the iron demand for a given $\mathrm{CO}_{2}$ removal would be one to two orders of magnitude greater than estimates based on the laboratory measurements (cf. Buesseler and Boyd, 2003). In addition to this problem, there has been only partial success in demonstrating that DIC uptake by iron fertilization actually results in carbon export from the surface ocean. The limited observational period of most experiments seems a likely reason for the failure to observe a significant export flux in many cases (Buesseler et al., 2004; de Baar et al., 2005). For example, in one of the few successful observations of particle fluxes, Bishop et al. (2004) used autonomous floats with optical measurements of the "carbon flux index" to show a large flux of particulate organic carbon at the SOFeX northern patch site beginning only 25 to 45 days after iron addition was initiated. Based on their measurements, Bishop et al. (2004) estimated a C export to Fe added ratio of $R_{\text {iron utilization }}^{\mathrm{C}: \mathrm{Fe}} 10000$ to 100000 , which is more in the range of what might be expected from the laboratory experiments.

The problems inherent in short term manipulation experiments have motivated a new series of observational studies at locations within HNLC regions where islands provide a local long-term source of iron. Such studies of natural iron fertilization at the Kerguelen plateau and Crozet Island in the Southern Ocean have detected a large excess particulate organic carbon export in iron fertilized regions relative to that in adjacent non-fertilized regions using the ${ }^{234} \mathrm{Th}$ deficit method. The ratio of the excess $\mathrm{C}$ export to $\mathrm{Fe}$ supply is estimated to be $R_{\text {iron utilization }}^{\mathrm{C}: \mathrm{Fe}}=53000$ across $100 \mathrm{~m}$ depth at Kerguelen at the time of observations (Blain et al., 2007). At Crozet Pollard et al. (2009) found that after the chlorophyll peak in the iron fertilized region and in the HNLC region, the mean daily rates of carbon export were similar. However, they calculated different bloom durations for each region by using ${ }^{234} \mathrm{Th} /$ opal ratios to close the silicate budget. The seasonal ratio of excess $\mathrm{C}$ export to $\mathrm{Fe}$ supply at Crozet was estimated to be $17200(5400-60400)$ at $100 \mathrm{~m}$ and 8600 at $200 \mathrm{~m}$. Estimates based on the seasonal DIC and Fe budgets at Kerguelen give a much higher seasonal mol C to mol Fe ratio of $R_{\text {iron utilization }}^{\mathrm{C} \text { :Fe }}=668000$, though a recent revision by Chever et al. (2010) dropped this to 154000 . The reason for the large remaining difference between the Kerguelen and Crozet seasonal estimates of $R_{\text {iron utilization }}^{\mathrm{C} \text { :Fe }}$ is not understood (e.g., Pollard et al., 2009).

Despite the large uncertainties, the natural iron fertilization studies and some of the iron manipulation studies have clearly demonstrated by now that iron fertilization of HNLC regions should eventually give rise to an increased particle export flux. What can we say about the physical-chemical efficiency $e_{\text {phys-chem }}$, i.e., the extent to which the resulting reduction in surface DIC will actually remove $\mathrm{CO}_{2}$ from the atmosphere? The short time span of the iron manipulation experiments is problematic for verification of the impact of iron fertilization on the air-sea balance of $\mathrm{CO}_{2}$. A typical airsea e-folding equilibration time for a $40 \mathrm{~m}$ mixed layer is of order 6 months (Sarmiento and Gruber, 2006), as contrasted with the time scale of a few weeks of the experiments. Thus, the air-sea $\mathrm{CO}_{2}$ flux estimated from the DIC deficit during the fertilization period is only a miniscule part of the carbon budget, an average of $8 \%$ of the DIC drawdown per de Baar et al. (2005). The time scale of the natural iron fertilization studies is more suitable, though still not ideal. Estimates of air-sea $\mathrm{CO}_{2}$ gas flux over a 75-day period during the Crozet Island experiment by Bakker et al. (2007) gave an average uptake of $700 \pm 600 \mathrm{mmol} \mathrm{m}^{-2}$ inside the fertilized patch versus $240 \pm 120 \mathrm{mmol} \mathrm{m}^{-2}$ outside the patch, for a net uptake of $460 \pm 580 \mathrm{mmol} \mathrm{m}^{-2}$ due to the added iron. Pollard et al. (2009) give a particulate organic carbon (POC) export of $960 \mathrm{mmol} \mathrm{m}^{-2}$ in the patch versus $290 \mathrm{mmol} \mathrm{m}^{-2}$ outside, for a net of $670 \mathrm{mmol} \mathrm{m}^{-2}$, with no uncertainty reported. The air-sea $\mathrm{CO}_{2}$ uptake in the Crozet iron fertilized region thus gives a physical-chemical efficiency of $e_{\text {phys-chem }} \sim 69 \%$, but with quite a large uncertainty. At Kerguelen, we use the 90 day seasonal carbon flux estimates of Jouandet et al. (2008) of $5400 \pm 1900 \mathrm{mmol} \mathrm{m}^{-2}$ inside the patch versus $1700 \pm 400 \mathrm{mmol} \mathrm{m}^{-2}$ outside the patch, and air-sea flux of $28 \pm 24 \mathrm{mmol} \mathrm{m}^{-2} \mathrm{~d}^{-1}$ inside the patch versus $-2.7 \pm 2.3 \mathrm{mmol} \mathrm{m}^{-2} \mathrm{~d}^{-1}$ outside the patch, $\times 90$ days $/ 2$ following their approach to account for the whole season, to calculate $e_{\text {phys }- \text { chem }}=37 \%$, again with a very large uncertainty. However, even the 75 and 90 day time periods over which the air-sea flux was estimated in the natural fertilization studies is insufficient to catch the full equilibration time of the surface DIC perturbation. More importantly, although such studies very likely capture a substantial fraction of the immediate response to iron fertilization, there are other longer term processes that can modify the overall chemical-physical efficiency of the iron fertilization, such as the global backflux of $\mathrm{CO}_{2}$ that results from reduction of atmospheric $\mathrm{CO}_{2}$ (cf., Gnanadesikan et al., 2003). Numerical models can play a crucial role in estimating the magnitude of such long-term feedbacks.

Until the addition of explicit representations of ecosystem processes and the iron cycle, the impact of iron fertilization on the air-sea $\mathrm{CO}_{2}$ balance and global biogeochemistry had to be simulated using macronutrient manipulation studies such as those used in most of the model simulations discussed earlier. In these studies, the putative effects of iron fertilization are simulated by assuming that iron fertilization reduces surface nutrient concentrations by formation and export of organic matter, which also removes a corresponding amount of dissolved inorganic carbon with standard stoichiometric ratios. Because of the absence of ecosystem and iron cycle model components, macronutrient manipulation studies are unable to simulate the biogeochemical 
response function, $R_{\text {iron utilization }}^{\mathrm{C}: \mathrm{Fe}}$ The patch Equatorial Pacific macronutrient depletion simulation of Gnanadesikan et al. (2003) using a Martin et al. (1987) power law remineralization profile gave an extremely low $e_{\text {phys-chem }}$ of $2.0 \%$ for the 100 year response of a one-time, one-month nutrient depletion scenario. Identical simulations for 50 years at the northwest Pacific SEEDS site by Matsumoto (2006) gave $e_{\text {phys-chem }} \sim 7 \%$ after 100 years. The difference between these two sites may be due in part to the mechanisms discussed by Jin et al. (2008) in their examination of $e_{\text {phys-chem }}$, namely the effective depth from which the DIC is removed by the nutrient depletion, and the thickness of the mixed layer, with shallower DIC removal depths and thinner mixed layers at the time of fertilization giving a higher efficiency of $\mathrm{CO}_{2}$ removal from the atmosphere. The depth of the remineralization is also an important factor in the response: if all the excess organic carbon exported from the surface of the ocean is allowed to sink to the ocean floor before being remineralized, the efficiency rises to $\sim 10 \%$ in the Equatorial Pacific and $\sim 12 \%$ in the northwest Pacific.

By contrast with the macronutrient depletion scenarios, Gnanadesikan et al. (2003) obtained an efficiency of $42 \%$ at their Equatorial Pacific site when macronutrients were added. In their discussion of their two sets of simulations, Gnanadesikan et al. (2003) suggest that the macronutrient depletion scenario is essentially simulating the effect of an iron fertilization where the iron is added and then lost at the end of the nutrient depletion event, whereas the macronutrient addition scenario is effectively an iron added and permanently retained scenario. Biogeochemical models including the iron cycle will likely fall somewhere between the two extremes of $e_{\text {phys-chem }}=2 \%$ and $42 \%$, as is the case with the scenarios discussed in this paper as well as the simulation study of $\mathrm{Au}-$ mont and Bopp (2006), who obtained an $e_{\text {phys-chem }}$ of $33 \%$ in their 100 year simulation of iron stress relief (cf. also the $e_{\text {phys-chem }}$ of 10-25\% obtained by Zeebe and Archer, 2005, albeit with a different simulation approach).

How are we to move forward in this "sea of uncertainty" (cf. Buesseler et al., 2008) where both field experiments and model simulations disagree with each other by one or more orders of magnitude in critical parameters such as the physical-chemical efficiency and biogeochemical response function, with only minimal understanding of why this is so? Clearly, a broad spectrum of experimental as well as modeling studies is required. As regards the models, ocean biogeochemical models with an explicit iron cycle as well as an ecosystem component, and which can therefore be used to examine both the biogeochemical response function $R_{\text {iron utilization }}^{\mathrm{C} \text { Fe }}$ and the physical-chemical efficiency $e_{\text {phys-chem, have been in existence for several years now (e.g., }}$ Moore et al., 2002b; Aumont et al., 2003; Dutkiewicz et al., 2005; Tagliabue and Arrigo, 2006). These models have been used to examine the effect of iron on biological productivity and the ocean nutrient distribution (e.g., Moore et al., 2002a; Aumont and Bopp, 2006; Tagliabue et al., 2008; Schneider et al., 2008; Moore and Doney, 2007), as well as on the atmosphere in response to changes in dust delivery at present and during the ice ages (e.g., Bopp et al., 2003). A major motivation for the study described in this paper is one such sensitivity study carried out by Dutkiewicz et al. (2006). A surprising finding from the Dutkiewicz et al. (2006) study was that the highest uptake of atmospheric $\mathrm{CO}_{2}$ occurred when iron was added in the equatorial Pacific HNLC region, with a much smaller uptake resulting from iron addition in the Southern Ocean HNLC region. This result differs dramatically from what we would have inferred from earlier macronutrient manipulation studies such as those of KVHISOUTH shown in Table 1.

The disagreement between the Dutkiewicz et al. (2006) results and previous studies was the original motivation for the organization of an Iron Fertilization Model Intercomparison Project (IFMIP) with the main initial purpose to examine the sensitivity of the iron fertilization response to the basic structure of the biogeochemistry models. In related work, Jin et al. (2008) carried out a series of sensitivity studies examining how the physical-chemical efficiency $e_{\text {phys-chem }}$ is related to the mixed layer thickness and depth within the surface ocean at which the enhanced removal of nutrients and DIC occurs. Our study examines the processes that determine the physical-chemical efficiency $e_{\text {phys-chem }}$, and the biogeochemical response function $R_{\text {iron utilization }}^{\mathrm{C}: \mathrm{Fe}}$.

\section{Model description and evaluation}

We describe here how the biogeochemical model and iron fertilization scenarios are set up, and we evaluate the control simulation and iron fertilization scenarios by comparing them with observations. The physical model is described in Appendix B.

\subsection{Biogeochemical model}

For ecology and biogeochemistry, we use an early generation of the GFDL TOPAZ model developed by Dunne et al. (2006). The full set of model equations and tables of the constants that we used in our simulations are given in the Supplementary Material. The model has eight dissolved inorganic variables: nitrate, ammonium, phosphate, silicate, oxygen, iron, carbon, and alkalinity. Phytoplankton processes are simulated with 5 functional groups, three that are solved explicitly (small and large phytoplankton as well as diazotrophs) and two that are solved implicitly (diatoms as a function of large phytoplankton, and coccolithophorids as a function of small phytoplankton). Growth of phytoplankton is based on a comprehensive representation of multinutrient limitation of phytoplankton with variable N:P:Fe:Si:Chl stoichiometry and physiology. Grazing is modeled implicitly as described by Dunne et al. (2005), as is particulate organic matter. Small and large phytoplankton are assumed to have an $\mathrm{N}: \mathrm{P}$ of $16: 1$ while diazotrophs have an $\mathrm{N}: \mathrm{P}$ of $50: 1$ after 
Letelier and Karl (1998). Dissolved organic matter is modeled explicitly as consisting of a labile component with an $\mathrm{N}: \mathrm{P}$ ratio of $16: 1$ and a lifetime of 3 months; and a semilabile component with separate $\mathrm{N}$ and $\mathrm{P}$ components with lifetimes of 18 years and 4 years, respectively (cf. Abell et al., 2000). The model includes denitrification in both the water column when oxygen falls below $5 \mathrm{mmol} \mathrm{m}^{-3}$, and in the sediments using the flux-based algorithm of Middelburg et al. (1996). The cycling of all organic C components is based on that of organic $\mathrm{N}$ with a fixed $\mathrm{C}: \mathrm{N}$ of 117:16. The model has two dissolved organic $\mathrm{C}$ pools corresponding to the two aforementioned labile and semi-labile dissolved organic matter components.

Phytoplankton growth rate is equal to a temperaturedependent maximum growth rate, times a dimensionless nutrient limitation term with a value between 0 and 1 , times an iron-light co-limitation term also with a value between 0 and 1. The nutrient limitation term is the minimum of nitrogen dependence, modeled as in Frost and Franzen (1992) as modified by Sharada et al. (2005), or phosphorus or silicic acid dependence (for diatoms only), both modeled as Michaelis-Menten kinetics. Figures 1a to $\mathrm{c}$ show the geographic distribution of which macronutrient is limiting for each type of phytoplankton averaged over the three summer months for each hemisphere. The general pattern is one of nitrogen limitation in the subtropics for both small and large phytoplankton, and phosphorus limitation in the subtropics for diazotrophs. The Equatorial Pacific upwelling HNLC region and subpolar and polar HNLC regions of the North Pacific and Southern Ocean are generally replete (defined as $\geq 0.965$ ) in $\mathrm{P}$ and $\mathrm{N}$ but limiting in Si for large phytoplankton (diatoms).

Iron and light limitation are simulated using a novel quotabased light-Fe colimitation approach developed by Dunne et al. (2006; see Supplementary Material) based on fitting the observations of Sunda and Huntsman (1997). This approach allows "luxury uptake" of iron so that the plankton are very effective at taking up iron even when it does not result in an immediate increase in growth rate. The calculation of the growth rate is based on Geider et al. (1997) with the Fe:N ratio and light supply modulating the Chl:N ratio. The half saturation constant for iron uptake by small phytoplankton and diazotrophs is $0.1 \mu \mathrm{mol} \mathrm{m}{ }^{-3}$, and that for large phytoplankton is $0.3 \mu \mathrm{mol} \mathrm{m}{ }^{-3}$. The final value of the Fe contribution to the light-Fe colimitation term is shown in Fig. 1d to $f$. This is calculated for the three summer months in each hemisphere by taking the ratio of the light-Fe colimitation term and dividing it by the light-Fe colimitation term that one gets if iron is replete. The estimate of the Fe contribution to the light-Fe colimitation term is generally between 0 and 0.2 for large phytoplankton in the traditional HNLC regions, and very near 1 everywhere else except the North Atlantic, where it drops to the 0.8 range. Small phytoplankton have the same pattern, but with less limitation. Diazotrophs are iron limited almost everywhere except where iron supply by dust is high.
The cellular C:Fe mole ratio that results from the independent $\mathrm{Fe}$ and $\mathrm{N}$ cycles varies between 56000 and 300000 for large phytoplankton and 4000 to 30000 for diazotrophs, with a global mean $\mathrm{C}$ :Fe ratio in exported organic matter of $148500 \mathrm{~mol} \mathrm{C}: \mathrm{mol} \mathrm{Fe}$. These cellular ratios are well within the bounds of the observations discussed in Sect. 1 and references therein.

Dissolved iron is modeled as a single fully complexed pool. It is removed from the ocean not only by phytoplankton uptake, but also by second order adsorption onto any particle form including ballast and particulate organic matter. It is remineralized along with organic matter in the water column and sediments. The removal of iron by adsorption at the surface of the ocean has a time scale of 10 years or longer everywhere, with the consequence that phytoplankton uptake is the dominant loss mechanism. By contrast, adsorption is the main mechanism for removal of iron in the deep ocean, where the removal time scale ranges between 40 and 300 years at a depth of $2000 \mathrm{~m}$. The aeolian flux of iron is that of Ginoux et al. (2001), with $2 \%$ of the iron assumed to be soluble in seawater. The total annual iron input from the atmosphere is $3.31 \times 10^{9} \mathrm{~mol} \mathrm{yr}^{-1}$ with an iron flux of $0.68 \times 10^{9} \mathrm{~mol} \mathrm{yr}^{-1}$ from the sediments. The Supplementary Material shows the iron cycling equations and Table 3.3 of the Supplementary Material summarizes all the parameters in the iron model and the observations on which they are based. The iron inventory in the model ocean after a 1000year spin-up is $575 \times 10^{9} \mathrm{~mol}$, giving a mean residence time of 144 years with respect to the combined dust and sediment inputs. This is within the bounds of previous estimates such as those discussed by Johnson et al. (1997). Since iron added by fertilization is treated the same as the "natural" iron, this means that the iron added by iron fertilization will remain in the ocean for decades to centuries before being scavenged.

Figures 2a through c show a comparison of observed and model predicted annual mean phosphate at the surface of the ocean after a 1000-year spin-up prior to carrying out the iron fertilization simulations. The correlation and relative standard deviation of surface phosphate in the model compared with the observations are 0.87 and 0.70 , respectively; the root mean square error is $0.46 \mathrm{mmol} \mathrm{m}^{-3}$ of phosphate. For phosphate in the ocean as a whole, the correlation is 0.86 and the relative standard deviation is 0.87 , which is comparable to the three models discussed by Schneider et al. (2008); the root mean square error is $0.34 \mathrm{mmol} \mathrm{m}^{-3}$. The model generally captures the spatial distribution of the high nutrient regions in the North and Equatorial Pacific and Southern Ocean, although it has too high phosphate in the tropics and subtropics and too low phosphate in the high latitudes of the North Pacific and Southern Ocean compared with the observations. The amount of carbon sequestered by iron fertilization is closely tied to the change in unutilized or preformed nutrients (Gnanadesikan and Marinov, 2008; Marinov et al., 2008). We thus expect that our model would tend to overpredict the response to iron fertilization in the tropics, and 

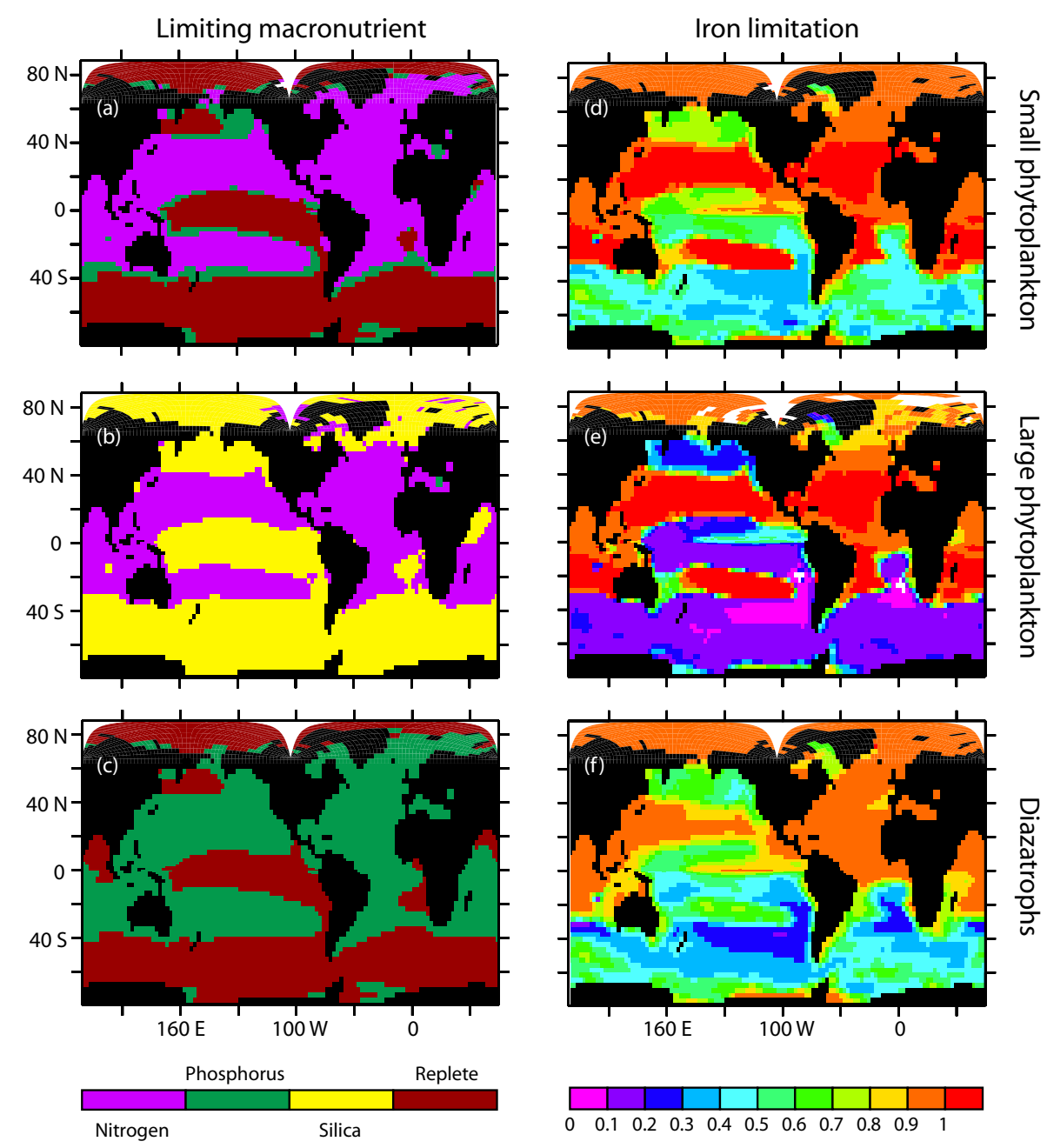

Fig. 1. The left column shows which macronutrient is limiting small phytoplankton (top), large phytoplankton (middle), and diazotrophs (bottom). These results are the three month summer averages for each hemisphere calculated from the control simulation after a 1000 year spin-up. Replete is defined as minimum limitation $\geq 0.965$. The right column shows the average summertime magnitude of the iron-light colimitation term divided by the magnitude of the iron-light co-limitation term when iron is assumed to be replete. In other words, it is a 0 to 1 measure of the iron contribution to iron-light colimitation.

under-predict the response to fertilization in the high latitudes relative to a model that is forced towards the observed nutrients.

Figures $2 \mathrm{~d}$ through $\mathrm{f}$ compare the observed and modeled oxygen distribution at $300 \mathrm{~m}$. We show this here because of the importance of denitrification for the response of the Equatorial Pacific to iron fertilization that we shall discuss later. The correlation and relative standard deviation of the model compared with the observations at this depth level are 0.88 and 1.18 , respectively, with a root mean square error of $43.3 \mathrm{mmol} \mathrm{m}^{-3}$. For the ocean as a whole, the correlation and relative standard deviation are 0.89 and 1.10 , respectively, with a root mean square error of $56.0 \mathrm{mmol} \mathrm{m}^{-3}$. In general, the model over-predicts the oxygen at $300 \mathrm{~m}$, which might lead one to expect lower denitrification. However, the volume of water in the model with oxygen concentrations less than $10 \mathrm{mmol} \mathrm{m}^{-3}$ is in fact almost 7 times as great as the corresponding volume in the observations $\left(27.2 \times 10^{15} \mathrm{~m}^{3}\right.$ versus $4.0 \times 10^{15} \mathrm{~m}^{3}$, respectively). This problem of too much suboxia is common to all the biogeochemical models we are familiar with, though we would also note that the data are also problematic at such low oxygen levels.

After the spin-up, a control simulation with no iron fertilization is carried out simultaneously with the four patch iron fertilization simulations described in the following section and whose names and locations are given in Table 2 with locations shown in Fig. 2. Figure 3 shows several key diagnostics from the control simulation at each of the four fertilization sites. All the figures are depth versus time contour plots for a period of two years. Each also includes the KPP mixed layer depth (see Appendix B for definition). Consider first the combined seasonality of the KPP mixed layer depth and 


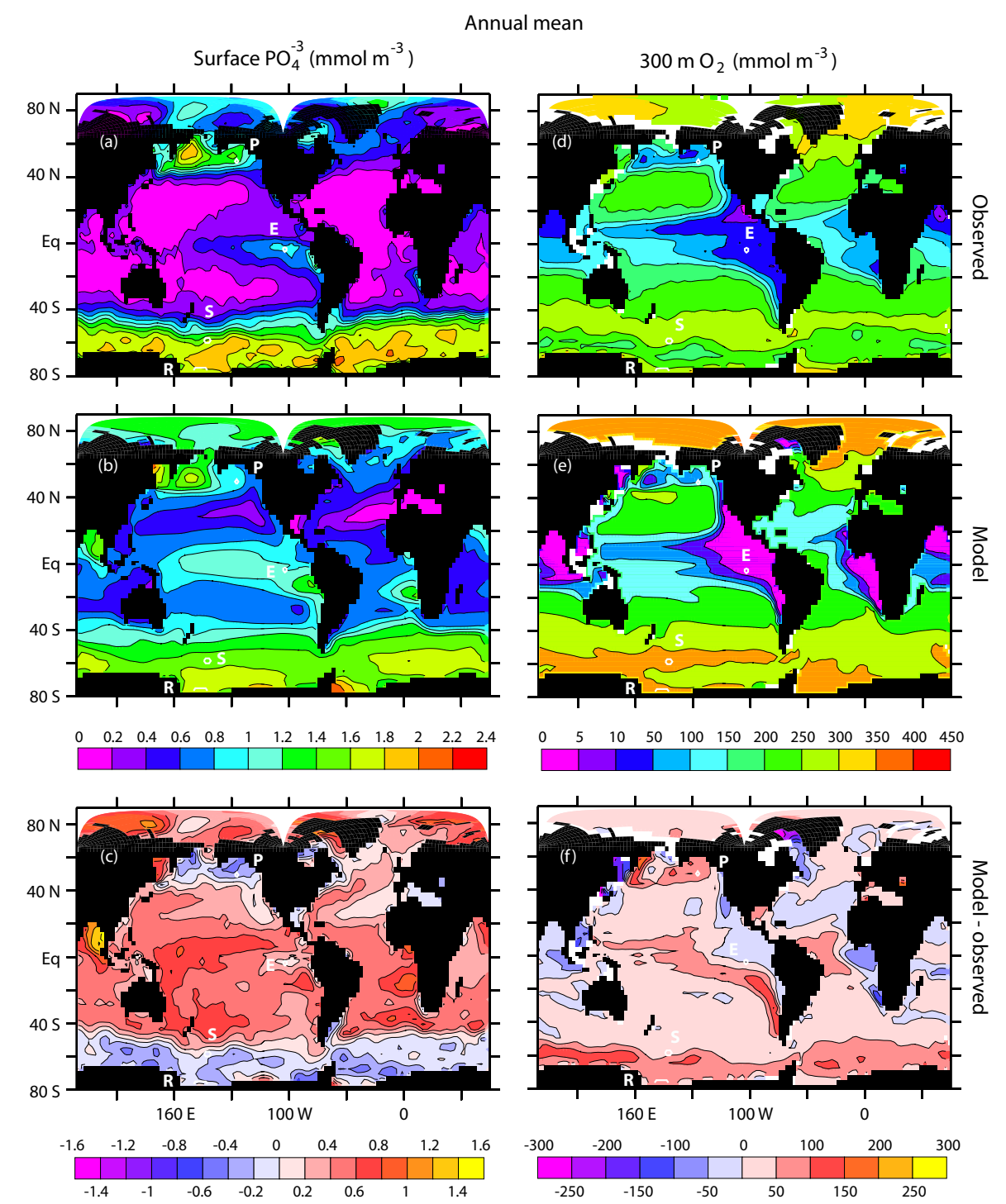

Fig. 2. (a) Observed annual mean of the phosphate at the surface of the ocean in mmol $\mathrm{m}^{-3}$ (Garcia et al., 2006) compared with (b) surface phosphate in the model. (c) shows the difference between model and observed. (d) and (e) show the oxygen concentration at $300 \mathrm{~m}$ in $\mathrm{mmol} \mathrm{m}^{-3}$ in the observations and model simulation, respectively, and (f) shows the model minus observed oxygen distribution. The figures also show the location of the four iron fertilization sites discussed in the paper. P is the PAPA site, E is the Equatorial Pacific site, $\mathrm{S}$ is the Southern Ocean site, and $\mathrm{R}$ is the Ross Sea site (see Table 2).

Table 2. Patch locations, bottom depth, and fertilization time in the 1x,10x, and 100x simulations.

\begin{tabular}{lrrrrc}
\hline Name & Location & $\begin{array}{r}\text { Number of } \\
\text { model grid cells }\end{array}$ & $\begin{array}{r}\text { Patch size } \\
\left(10^{3} \mathrm{~km}^{2}\right)\end{array}$ & $\begin{array}{r}\text { Bottom depth } \\
\text { in model (m) }\end{array}$ & $\begin{array}{c}\text { Month of } \\
\text { fertilization }\end{array}$ \\
\hline PAPA (North Pacific) & $50.0^{\circ} \mathrm{N}, 145^{\circ} \mathrm{W}$ & 2 & 72.3 & 4331 & May \\
Equatorial Pacific & $3.5^{\circ} \mathrm{S}, 104^{\circ} \mathrm{W}$ & 1 & 106.5 & 3453 & September \\
Southern Ocean & $58.5^{\circ} \mathrm{S}, 171^{\circ} \mathrm{W}$ & 2 & 116.3 & 4509 & October \\
Ross Sea & $76.0^{\circ} \mathrm{S}, 176^{\circ} \mathrm{W}$ & 4 & 103.9 & 545 & January \\
\hline
\end{tabular}




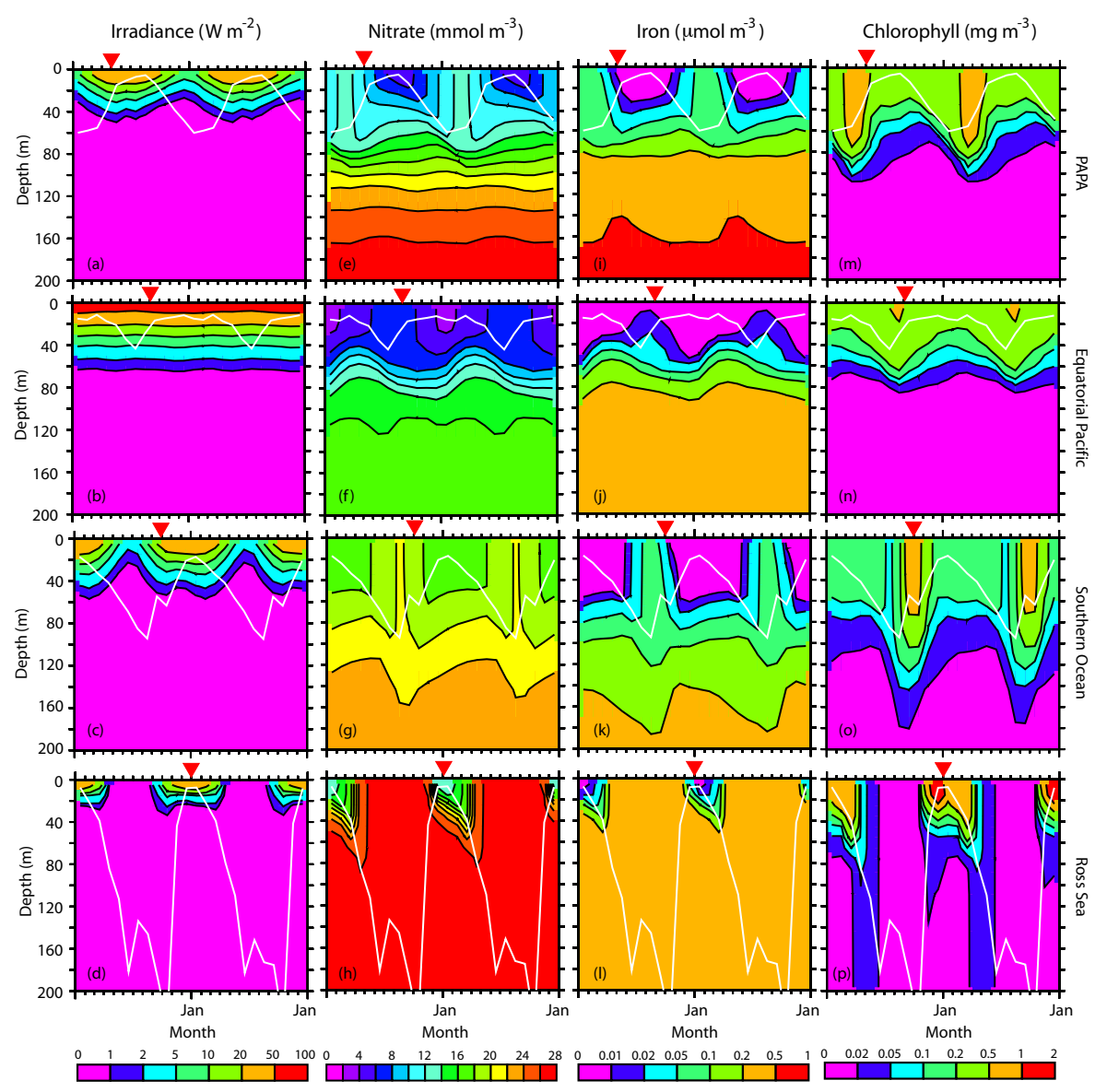

Fig. 3. Results of the control simulation contoured as a function of depth versus time at each of the four iron fertilization sites. The white line is the KPP mixed layer depth defined in the text. The red arrow at the top is the month when iron is added in the 1x, 10x, and 100x fertilization scenarios. Each row is a separate site with PAPA at the top, the Equatorial Pacific and Southern Ocean in the middle two rows, and the Ross Sea at the bottom. The first column shows irradiance in $\mathrm{W} \mathrm{m}^{-2},(\mathbf{a}-\mathbf{d})$; the second column shows nitrate concentration in mmol $\mathrm{m}^{-3},(\mathbf{e}-\mathbf{h})$; the third column shows iron concentration in $\mu \mathrm{mol} \mathrm{m}^{-3}$, (i-l); and the final column shows chlorophyll concentration in $\mathrm{mg} \mathrm{m}{ }^{-3}$ ( $\left.\mathbf{m}-\mathbf{p}\right)$. These are all for two years at the start of the control simulation.

irradiance shown in Figs. 3a to d. At PAPA, the Equatorial Pacific site, and the subpolar Southern Ocean site, the KPP mixed layer depth varies seasonally but never goes deeper than $100 \mathrm{~m}$. By contrast, the Ross Sea site has a KPP mixed layer depth of greater than $100 \mathrm{~m}$ for 6 months of the year. As with mixed layer depth, the light supply at the Equatorial Pacific site has very little seasonal variability. However, the seasonality in light gets progressively stronger as one goes from PAPA to the Southern Ocean site and Ross Sea site, where irradiance is below $5 \mathrm{~W} \mathrm{~m}^{-2}$ for 6 months a year. One would expect that adding iron to the ocean during the wintertime periods of deeper mixed layers and low light levels at PAPA, the South Pacific site, and, especially, the Ross Sea site, would be less efficient than at other times of the year. Indeed, this seasonality of the light supply and mixed layer depths is, we believe, one reason that Dutkiewicz et al. (2006) found a less efficient response to continuous iron addition in the high latitude Southern Ocean than in the Equatorial Pacific.
The mixed layer depth is crucial to determining the average irradiance level experienced by phytoplankton in the upper euphotic zone, and thus the response of the system to iron fertilization. Figure 4 shows a comparison of the model mixed layer depths with mixed layer depths determined from observations. The figure shows model mixed layer depths calculated two ways using: (1) a buoyancy criterion of $0.0003 \mathrm{~m} \mathrm{~s}^{-2}$, and (2) the KPP mixed layer depth as defined in Appendix B and shown in Fig. 3. Figure 4 shows that, except at the Ross Sea site, the buoyancy based model mixed layer depths are generally close to but always deeper than the KPP mixed layer depth. The greater depth of the buoyancy based mixed layer estimate is as expected given that the KPP mixed layer is based on the actual turbulent mixing and convective overturning specified by the model, whereas the buoyancy based mixed layer estimate reaches below the base of the actual layer of homogenized water. The much greater depth of the buoyancy based mixed layers than 

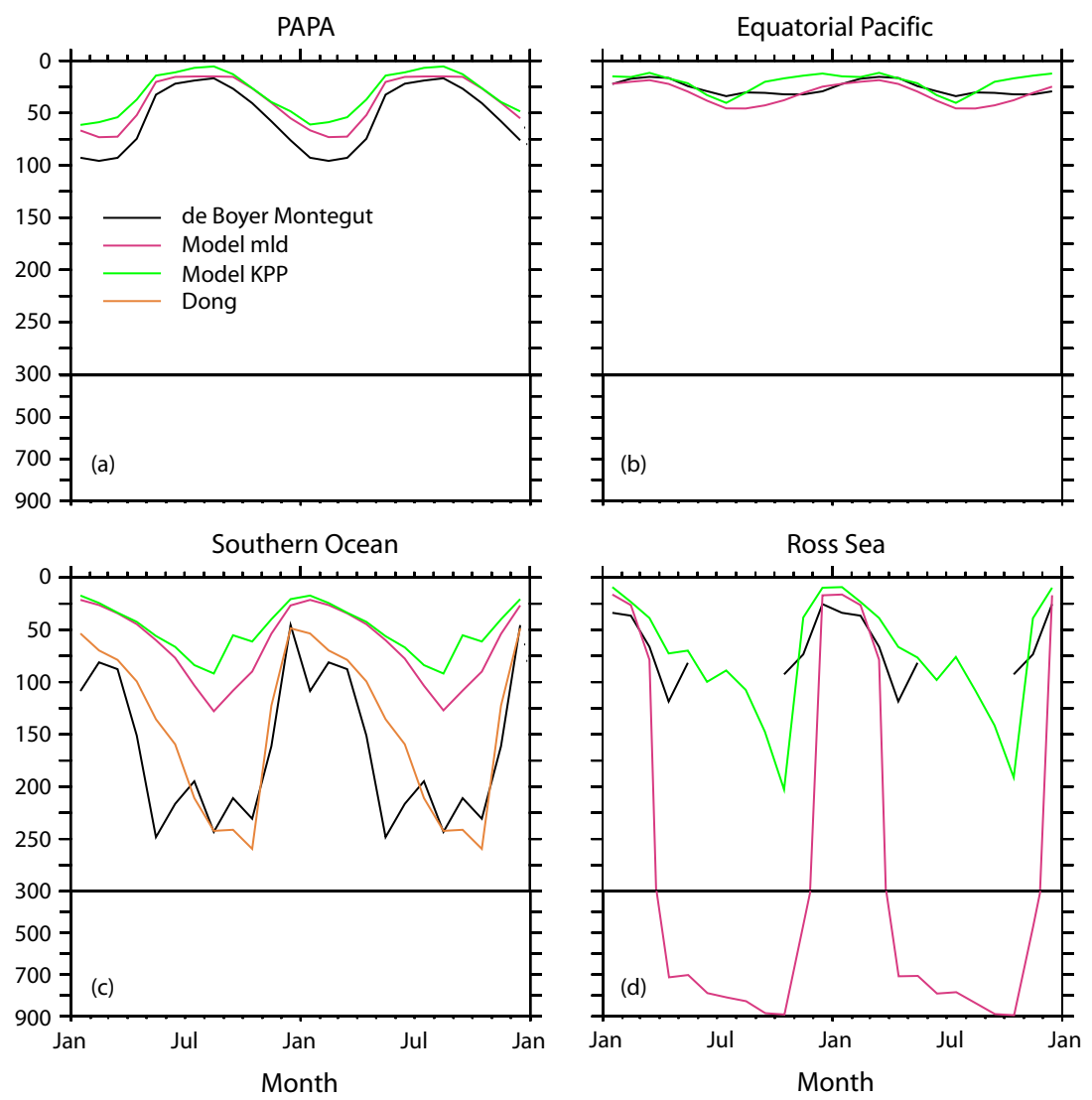

Fig. 4. Mixed layer depths determined from observations by de Boyer Montégut et al. (2004) at all four fertilization sites and Dong et al. (2008) at the Southern Ocean fertilization site. The de Boyer Montégut et al. (2004) mixed layer depths are determined by averaging together estimates of the mixed layer depth calculated from individual temperature profiles using a temperature criterion of $\Delta \mathrm{T}=0.2^{\circ} \mathrm{C}$ referenced to the value at $10 \mathrm{~m}$ depth. Dong et al. (2008) use potential density calculated from Argo float data and only provide estimates for the Southern Ocean region. Two versions of the model mixed layer depths are shown using (1) a buoyancy criterion of $0.0003 \mathrm{~m} \mathrm{~s}-2$ ("Model mld") and (2) the KPP mixed layer depth ("Model KPP") as defined in Appendix B and shown in Fig. 3.

the KPP mixed layer at the Ross Sea site is because vertical stratification at this site in the model is extremely low.

Comparing the de Boyer Montégut et al. (2004) mixed layer depth estimate with the model derived buoyancy based mixed layer depth in Fig. 4a and b shows that the model is generally in good agreement with observations at both the PAPA and Equatorial Pacific sites, where the model is $\sim 10$ to $20 \mathrm{~m}$ shallower and $\sim 0$ to $20 \mathrm{~m}$ deeper than observations, respectively. The model buoyancy based mixed layer depth is shallower than the Dong et al. (2008) observations by 25 to $50 \mathrm{~m}$ in the summertime and $\sim 100 \mathrm{~m}$ in the wintertime at the Southern Ocean site (Fig. 4c), which means that the model will underestimate the effect of light limitation on phytoplankton growth at this site. Finally, we see at the Ross Sea site that the buoyancy based model mixed layer depth agrees with de Boyer Montégut et al. (2004) during the early months of the year, but then deepens a couple of months earlier than the observations and shallows a couple of months later than the observations (Fig. 4d). However, there is much better agreement of the KPP mixed layer depth with the observa- tional temperature based estimate, which suggests that the problem at the Ross Sea site is not so much that the mixed layer depth is incorrectly simulated as that the model is too weakly stratified.

In Figs. 3e to p, we show the time evolution of nitrate, iron, and chlorophyll at the four sites in the control simulation. We see from the nitrate and chlorophyll contour plots that all four locations fit the classical definition of an HNLC regime, with nitrate concentrations that never become depleted, and chlorophyll concentrations that drop precipitously after the spring bloom at a time when the nitrate concentrations, light supply, and mixed layer depth are all still ideal for phytoplankton growth. We note that PAPA and the Equatorial Pacific site drop to relatively low nitrate concentrations during the summertime nutrient minimum: $4.3 \mathrm{mmol} \mathrm{m}^{-3}$ and $3.7 \mathrm{mmol} \mathrm{m}^{-3}$, respectively; as contrasted with the much higher summertime nutrient minima of 17.1 and $12.5 \mathrm{mmol} \mathrm{m}^{-3}$ at the South Pacific site and Ross Sea sites, respectively. All else being equal, we might expect a greater conversion of preformed to remineralized nutrients 
and thus a bigger response of the air-sea $\mathrm{CO}_{2}$ balance to fertilization at the latter two sites (cf. Marinov et al., 2008; Gnanadesikan and Marinov, 2008).

\subsection{Iron fertilization simulations}

The iron fertilization simulations are carried out at the end of a 1000-year spin-up of the biogeochemistry model at which time the global air-sea $\mathrm{CO}_{2}$ flux is drifting at a rate of $0.08{\mathrm{PgC} \mathrm{yr}^{-1}}^{-1}$. The iron fertilization scenarios are based on the IFMIP protocol, which, in turn, is based to the greatest extent possible on the MIT adjoint model study of Dutkiewicz et al. (2006). The adjoint model makes it possible to efficiently calculate the separate effect of iron fertilization on a grid point by grid point basis for every single surface grid point in the model. However, this option was not available to other IFMIP participants and so we chose to do patch fertilization at the four representative locations given in Table 2 and illustrated in Fig. 2. These sites are all in the Pacific Ocean and span the three major HNLC regions of the North and Equatorial Pacific and Southern Ocean. Motivated by the Southern Ocean biogeochemical divide described by Marinov et al. (2006), to the north of which nutrient depletion affects primarily the global biological export production, and to the south of which nutrient depletion affects primarily the air-sea balance of carbon dioxide, we chose two sites in the South Pacific: the subpolar region of the Southern Ocean north of the divide, and the polar Ross Sea region south of the divide.

The size of the iron patches for each IFMIP model was supposed to be as close as possible to the size of the cell area of the MIT grid location closest to the patch. However, in our model simulations, we chose to fertilize an integral number of grid cells that would make the area of each of our four fertilization sites as close as possible to each other so that the total amount of iron added in each case would be approximately the same (see columns 3 and 4 of Table 2). Following Dutkiewicz et al. (2006), bioavailable iron is added to the ocean continuously at a rate of $0.02 \mathrm{mmol} \mathrm{m}^{-2} \mathrm{yr}^{-1}$, which was chosen by them as representative of the background aeolian flux in their model, which ranges from a low of 0.001 to $0.5 \mathrm{mmol} \mathrm{m}^{-2} \mathrm{yr}^{-1}$. The original IFMIP specification was that simulations were to be carried out for 10 years, but we show here results of simulations that have been carried out for 100 years.

We performed additional sensitivity studies using the same IFMIP bioavailable iron input of $0.02 \mathrm{mmol} \mathrm{m}^{-2} \mathrm{yr}^{-1}$. The principal ones we use in our discussion below are: (1) a one month one time fertilization, which is the time scale used by Gnanadesikan et al. (2003); (2) fertilization for one month per year for 10 years (10x as much iron as case (1)); (3) fertilization for one month per year for 100 years $(100 \mathrm{x}$ as much iron as case (1)); and (4) continuous fertilization for 100 years as in Dutkiewicz et al. (2006) (1200x as much iron as case (1)). In what follows, we shall refer to these four sce- narios as the 1x, 10x, 100x, and 1200x cases, respectively. In the one month and one month per year simulations, the month of iron addition was chosen to be immediately after the spring bloom when the iron concentration drops below the $0.01 \mu \mathrm{mol} \mathrm{m}{ }^{-3}$ contour (see Fig. 3i to 1 and column 6 of Table 2). With four different fertilization locations, this represents a total of $4 \times 4=16$ separate simulations.

The four sites selected for this study were chosen because they are located in HNLC regions, and because of their proximity to the sites of actual in situ iron fertilization experiments (Table 3). A distinct difference between the model iron addition simulations and the actual in situ iron fertilization experiments is the timescale and rate of deployment of the iron. In the $1 \mathrm{x}$ model simulations described in this paper, iron was added continuously for one month, whereas during in situ experiments iron was added over one to four patches, each lasting $\sim 24 \mathrm{hr}$ and spread out over a period of up to a few weeks. The difference in the amount of iron added is also notable: $\sim 90 \mathrm{~g} \mathrm{~km}^{-2}$ over a month in the $1 \mathrm{x}$ model simulations, versus an initial $\sim 24 \mathrm{hr}$ deployment of iron in in situ patches of between 1400 and $5900 \mathrm{~g} \mathrm{~km}^{-2}$ (Table 3). In order to be able to better compare the model simulations with the in situ iron addition experiments, we carried out an additional series of one month $(1 \mathrm{x})$ iron fertilization simulations with flux multiples of 5x (1x-5), 10x (1x-10) and 100x (1x-100) times the original flux of $\sim 90 \mathrm{~g} \mathrm{~km}^{-2}$, which give cumulative iron additions of $\sim 500 \mathrm{~g} \mathrm{~km}^{-2}, 900 \mathrm{~g} \mathrm{~km}^{-2}$ and $9000 \mathrm{~g} \mathrm{~km}^{-2}$, respectively, thereby spanning the actual in situ iron addition experiments. Furthermore, in order to compare our southern ocean site simulations with results from the continuous natural iron fertilization studies at Kerguelen (Blain et al., 2007) and Crozet (Pollard et al., 2009), we ran a further set of flux multiples of the continuous iron fertilization 1200x scenario, which we refer to as $1200 x-5,1200 x-10$, and $1200 \mathrm{x}-100$ in the last column of Table 3.

The gross biological response of model iron additions averaged over the month of iron addition compares well with in situ iron addition experiments. In general in situ experiments have resulted in about a 10 -fold increase in chlorophyll concentration, a 2-fold increase in $\mathrm{Chl}: \mathrm{C}$ and a community shift from small to large phytoplankton (Table 3). The PAPA model location of $50^{\circ} \mathrm{N} 145^{\circ} \mathrm{W}$, and fertilization month of May was near the 2002 SERIES $\left(50^{\circ} \mathrm{N} 144^{\circ} \mathrm{W}\right.$, July) in situ iron addition (Boyd et al., 2005). The PAPA $1 \mathrm{x}-10$ and 1x-100 model simulations obtained chlorophyll concentrations of $2.2-5.2 \mathrm{mg} \mathrm{m}^{-3}$, Chl:C ratio increases from 0.008 to between 0.015 and $0.019 \mathrm{~g}: \mathrm{g}$, and a community composition shift from $15 \%$ large phytoplankton to between 50 and $76 \%$ large phytoplankton (Table 3). The nearby SERIES iron addition experiment had a similar response, with maximum chlorophyll concentrations of $6.3 \mathrm{mg} \mathrm{m}^{-3}$, a doubling of the $\mathrm{Chl}: \mathrm{C}$ ratio in small phytoplankton from 0.004 to $0.008 \mathrm{~g}: \mathrm{g}$, a 4-fold increase of the Chl:C ratio in large phytoplankton from 0.005 to $0.024 \mathrm{~g}: \mathrm{g}$, and a floristic shift of large phytoplankton from 26\% to 86\% (Table 3; Boyd et al., 2005; Marchetti 


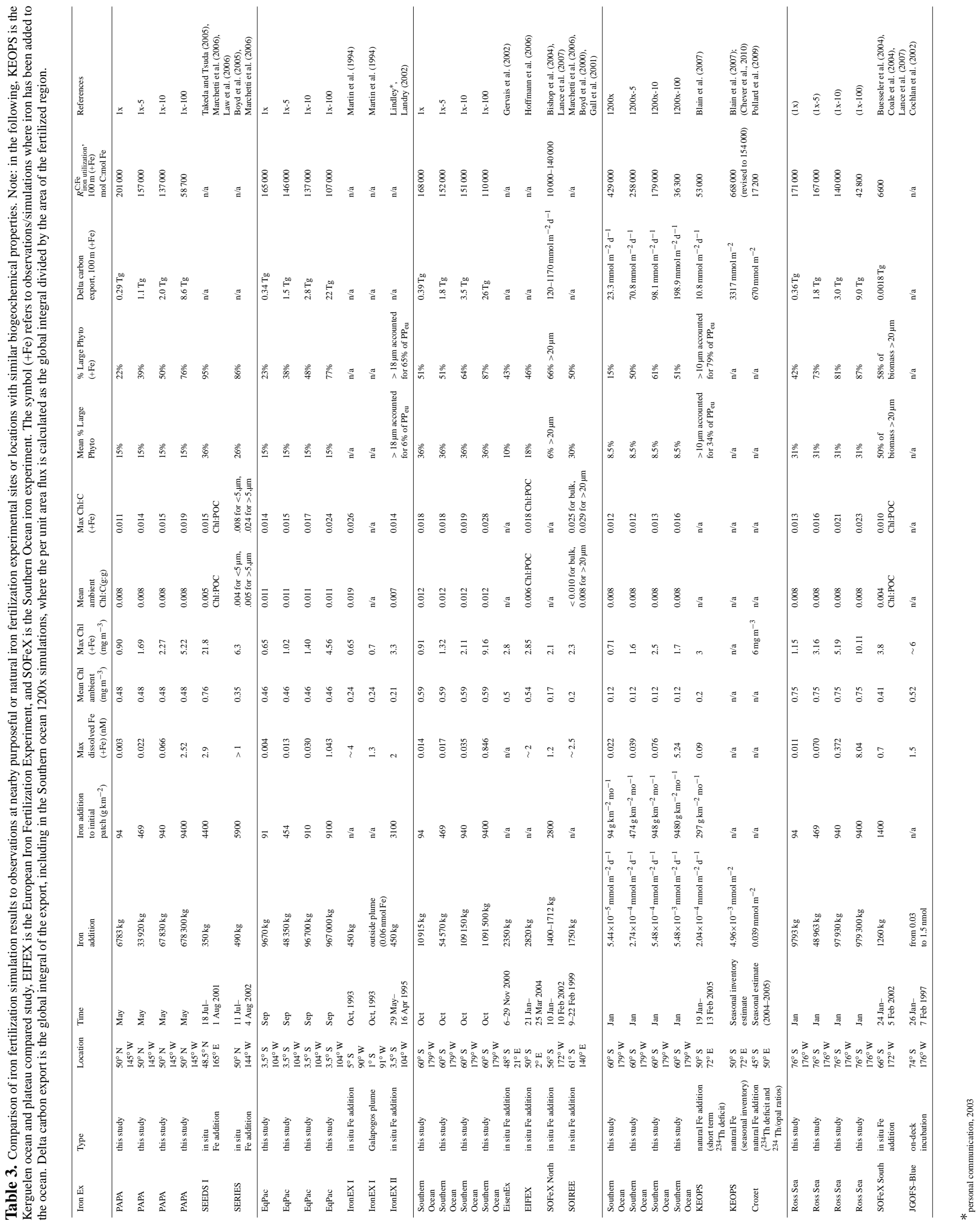


et al., 2006). The model simulations and in situ experiments also compared well at the other three sites, where the $1 \mathrm{x}-10$ model simulations at Eqpac, Southern Ocean and Ross Sea reached a peak chlorophyll concentration of 1.4, 2.1 and 5.2, respectively, while IronExII (Landry, 2002), SOFeX North (Lance et al., 2007) and SOFeX South (Coale et al., 2004) reported maximum chlorophyll concentrations of 3.3, 2.1 and $3.8 \mathrm{mg} \mathrm{m}^{-3}$, respectively (Table 3 ).

There have been very few in situ measurements of carbon export associated with iron addition and they are limited to the Southern Ocean. Bishop et al. (2004) estimated an $R_{\text {iron utilization }}^{\mathrm{C} ; \mathrm{Fe}}$ of between 10000 and $100000 \mathrm{~mol} \mathrm{C}$ :mol Fe for the SOFeX North experiment (Coale et al., 2004). At the Southern Ocean site, which is the most physically similar to the SOFeX study, the $1 \mathrm{x}, 1 \mathrm{x}-5,1 \mathrm{x}-10$ and $1 \mathrm{x}-100$ model simulations predict an $R_{\text {iron utilization }}^{\mathrm{C} F \mathrm{Fe}}$ of between 168000 and 110000 mol C:mol Fe (Table 3), which is higher than the observational estimate. Poleward of the Southern Boundary of the Antarctic Circumpolar Current, in an environment similar to that of our Ross Sea site, Buesseler et al. (2004) estimated $R_{\text {iron utilization }}^{\mathrm{C} ; \mathrm{Fe}}=6600 \mathrm{~mol} \mathrm{C:mol} \mathrm{Fe}$ in the SOFeX South experiment (Coale et al., 2004). The Ross Sea 1x model suite gives a much higher $R_{\text {iron utilization }}^{\mathrm{C} \text { Fe between } 42800 \text { and }}$ $171000 \mathrm{~mol} \mathrm{C}: \mathrm{mol} \mathrm{Fe}$. The spatial and temporal time scales may play an important role in explaining the bias towards high $R_{\text {iron utilization }}^{\mathrm{C} ; \mathrm{Fe}}$ in the model simulations. In situ observational estimates were made from carbon export measurements below the highly dynamic patch during the enrichment and assuming no loss in iron, whereas the model based estimates integrate all the carbon export over the whole ocean for the entire month of iron addition.

Observations at the natural fertilization Kerguelen Plateau (KEOPS) and Crozet studies were also used to esti-

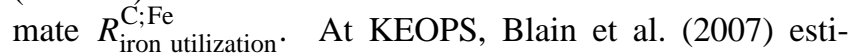
mated a short term $R_{\text {iron utilization }}^{\mathrm{C} \text { Fe }} 53000 \mathrm{~mol} \mathrm{C}: \mathrm{mol} \mathrm{Fe}$, in the upper $100 \mathrm{~m}$, and $R_{\text {iron utilization }}^{\mathrm{C} \text {; }}=70000 \mathrm{~mol} \mathrm{C}: \mathrm{mol} \mathrm{Fe}$ in the upper $200 \mathrm{~m}$. Using seasonal data, Blain et al (2007) calculated $R_{\text {iron utilization }}^{\mathrm{C} F}=668000 \mathrm{~mol} \mathrm{C}: \mathrm{mol} \mathrm{Fe}$ at the Kergulean Plateau, subsequently revised to 154000 by Chever et al. (2009); and Pollard et al. (2009) estimated $R_{\text {iron utilization }}^{\mathrm{C} ; \mathrm{Fe}}=17200 \mathrm{molC}: \mathrm{mol} \mathrm{Fe}$ at $100 \mathrm{~m}$ and 8600 at $200 \mathrm{~m}$ at Crozet. Based on the iron supply, the simulations to which these seasonal results are most appropriately compared are the continuous iron fertilization 1200x, 1200x-5, and 1200x-10 cases: the KEOPS short-term estimate has a diurnal iron flux most like that of 1200x-5; the seasonal KEOPS estimate of the iron flux divided by the 90 day duration of the bloom in the $+\mathrm{Fe}$ area gives a mean iron delivery of $5.5 \times 10^{-5} \mathrm{mmol} \mathrm{m}^{-2} \mathrm{~d}^{-1}$, which is comparable to our 1200x simulation; whereas the Crozet seasonal flux divided by the 61 day duration of the bloom in that region gives a mean iron delivery of $6.5 \times 10^{-4} \mathrm{mmol} \mathrm{m}^{-2} \mathrm{~d}^{-1}$, which is comparable to our 1200x-10 simulation. The simulation results shown in Table 3 are the average for the month of Jan- uary during the middle of the bloom. The models predict an $R_{\text {iron utilization }}^{\mathrm{C} \text {; } \mathrm{Fe}}$ of between 429000 in the $1200 \mathrm{x}$ simulation, and 179000 in the $1200 \mathrm{x}-10$ simulation. The model simulations tend to be higher than, but arguably in reasonable agreement with the KEOPS results, given the uncertainties, but are much higher than the Crozet results. The bias towards higher $R_{\text {iron utilization }}^{\mathrm{C} \text {; }}$ in model simulations than in the observational estimates is consistent with a possible undersampling of carbon export in the observational estimates, as suggested earlier for the iron fertilization experiments.

While there are no in situ biogeochemical response functions in the North and Equatorial Pacific to compare the models to, it is noteworthy that the 4 model regions had similar biogeochemical response functions in the $1 \mathrm{x}$ runs, ranging between $201000 \mathrm{~mol} \mathrm{C}: \mathrm{mol} \mathrm{Fe}$ at PAPA and $165000 \mathrm{~mol} \mathrm{C}: \mathrm{mol} \mathrm{Fe}$ at Eqpac. In all regions, additional Fe $(1 \mathrm{x}-5,1 \mathrm{x}-10$, and $1 \mathrm{x}-100)$ resulted in lower biogeochemical response functions. The most precipitous drop occurred at PAPA and Ross Sea (a 4-fold drop between the 1x and 1x100 model runs), while the EqPac and Southern Ocean regions declined more modestly.

\section{Results}

We discuss first the perturbation export production, then the nitrate, iron, and oxygen redistribution resulting from iron fertilization, and finally the perturbation air-sea $\mathrm{CO}_{2}$ flux.

\subsection{Response of export production}

The initial response of the annual particulate carbon export $\left(\mathrm{POC}\right.$ plus $\left.\mathrm{CaCO}_{3}\right)$ to iron fertilization is very rapid in this model (Figs. 5a to d), with the peak export in the 1 month per year fertilization scenarios $(1 \mathrm{x}, 10 \mathrm{x}$, and 100x) occurring during the month of fertilization, then dropping back to near zero after 2 to 3 months. Except at the Equatorial Pacific site, the annual carbon export production continues to grow modestly from one year to the next as more iron is added in the $10 x, 100 x$, and 1200x cases until it saturates on a time scale of a few decades in the 100x and 1200x cases (Figs. 5f to h). When fertilization is terminated in the $1 \mathrm{x}$ and $10 \mathrm{x}$ cases, the perturbation export production plunges almost instantaneously back to near zero. The behavior at the Equatorial Pacific site is atypical because of a major loss of nitrate by denitrification, as discussed in Sect. 3.2.

As one would expect from the relatively constant annual export production during the fertilization period in Figs. $5 \mathrm{f}$ to $\mathrm{h}$, the cumulative total carbon export results in Figs. $5 \mathrm{j}$ to 1 show an almost linear increase with fertilization time at all sites (again with the exception of the Equatorial Pacific). Furthermore, the linear scaling with amount of iron added works reasonably well even after the fertilization is terminated, with the $1 \mathrm{x}$ and $10 \mathrm{x}$ cases showing roughly $1 / 100$ th and $1 / 10$ th of the cumulative export production in the 100x case, and the 

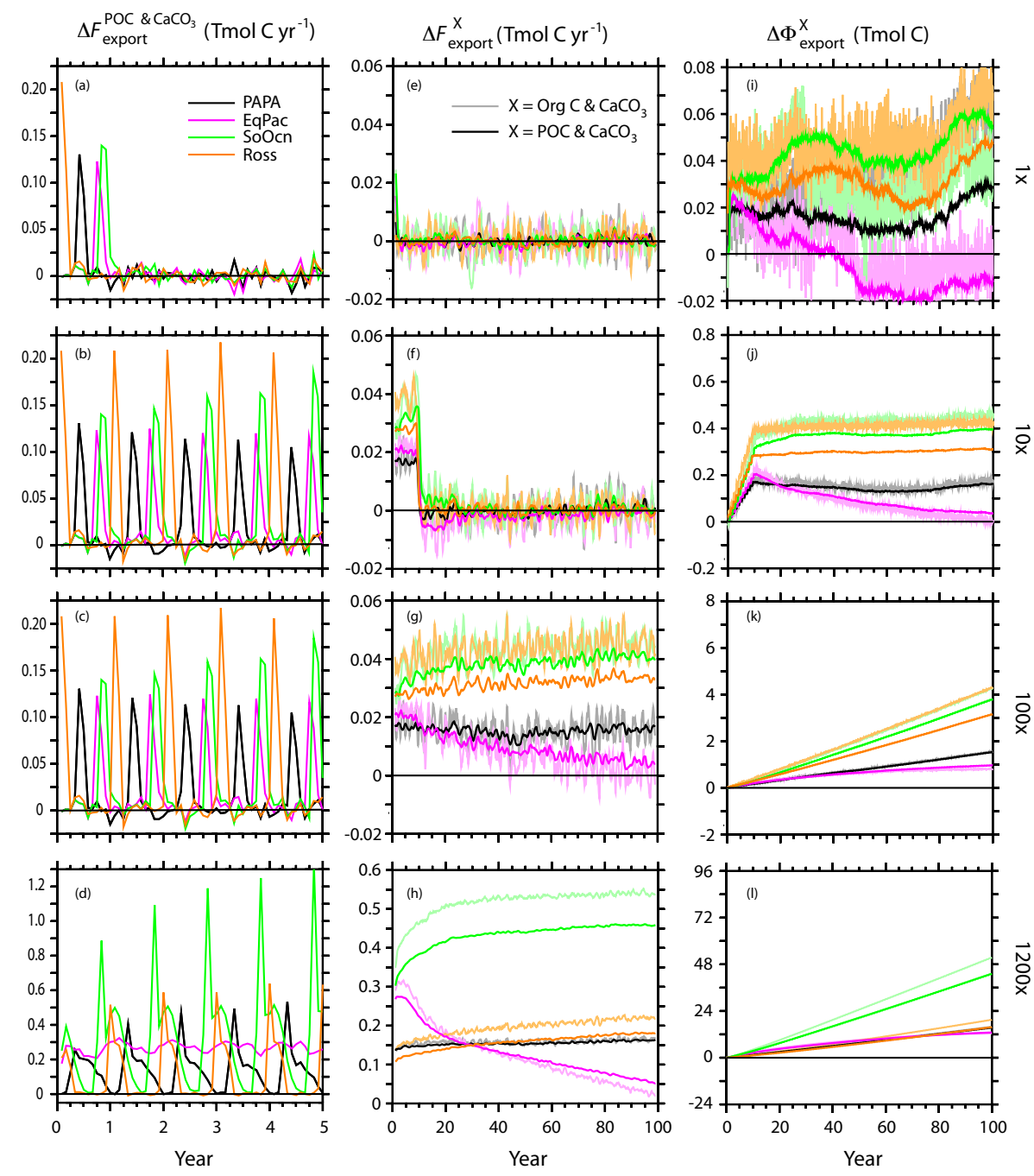

Fig. 5. (a-d) show the perturbation response of the monthly particulate organic carbon (POC) and $\mathrm{CaCO}_{3}$ export production $\Delta F_{\text {export }}^{\mathrm{POC} \& \mathrm{CaCO}_{3}}$ over the first 5 years for better resolution (see Appendix A for a definition of $\Delta F_{\text {export }}^{\mathrm{POC} \& \mathrm{CaCO}_{3}}$ and related terms). (e-h) show the monthly carbon export $\Delta F_{\text {export }}^{\mathrm{X}}$ over the first 100 years. The light colored lines show total carbon, $X=\operatorname{Org} \mathrm{C} \& \mathrm{CaCO}_{3}$, and the dark colored lines show only the particulate component of organic carbon, $X=\mathrm{POC} \& \mathrm{CaCO}_{3}$. (i-l) show the cumulative export of carbon $\Delta \Phi_{\text {export }}^{\mathrm{X}}$, with $X$ as above. We define export as the net downward flux across a depth of $98 \mathrm{~m}$. The rows correspond to the 1x, 10x, 100x, and 1200x cases from top to bottom. The flux of dissolved and living organic matter in the Org $\mathrm{C}$ component is very noisy, and the total carbon export fluxes in the middle and right hand column were heavily smoothed twice with a 12-month boxcar filter in order to make the different results distinguishable. Note that the POC \& $\mathrm{CaCO}_{3}$ export component accounts for most of the export flux at PAPA and the Equatorial Pacific sites, but misses a significant component of the total carbon export at the other two sites.

1200x case showing approximately 12 times the response of the 100x case. (Note that the vertical axes of Fig. 5i to 1 are scaled according to the total amount of iron added.) Aside from the Equatorial Pacific, the one significant exception to this scaling is the huge drop in the cumulative Ross Sea response to iron fertilization in the $1200 \mathrm{x}$ case versus the $100 \mathrm{x}$ case. This drop is due to the highly unfavorable wintertime mixed layer and irradiance conditions (see Fig. 3d) which results in Ross Sea biological production shutting down completely for 5 months from June to October (Fig. 3p). Iron added during this period in the $1200 \mathrm{x}$ case is swept out of the surface into the deep ocean without influencing the export production (see Sect. 3.2).

\subsection{Response of iron, nitrate, and oxygen distributions}

We show in Fig. 6 an analysis at year 100 of the impact of the 1200x iron fertilization simulation on the horizontally integrated vertical iron, nitrate, oxygen, and DIC distributions, and in Fig. 7, the impact of the 1200x simulation on 

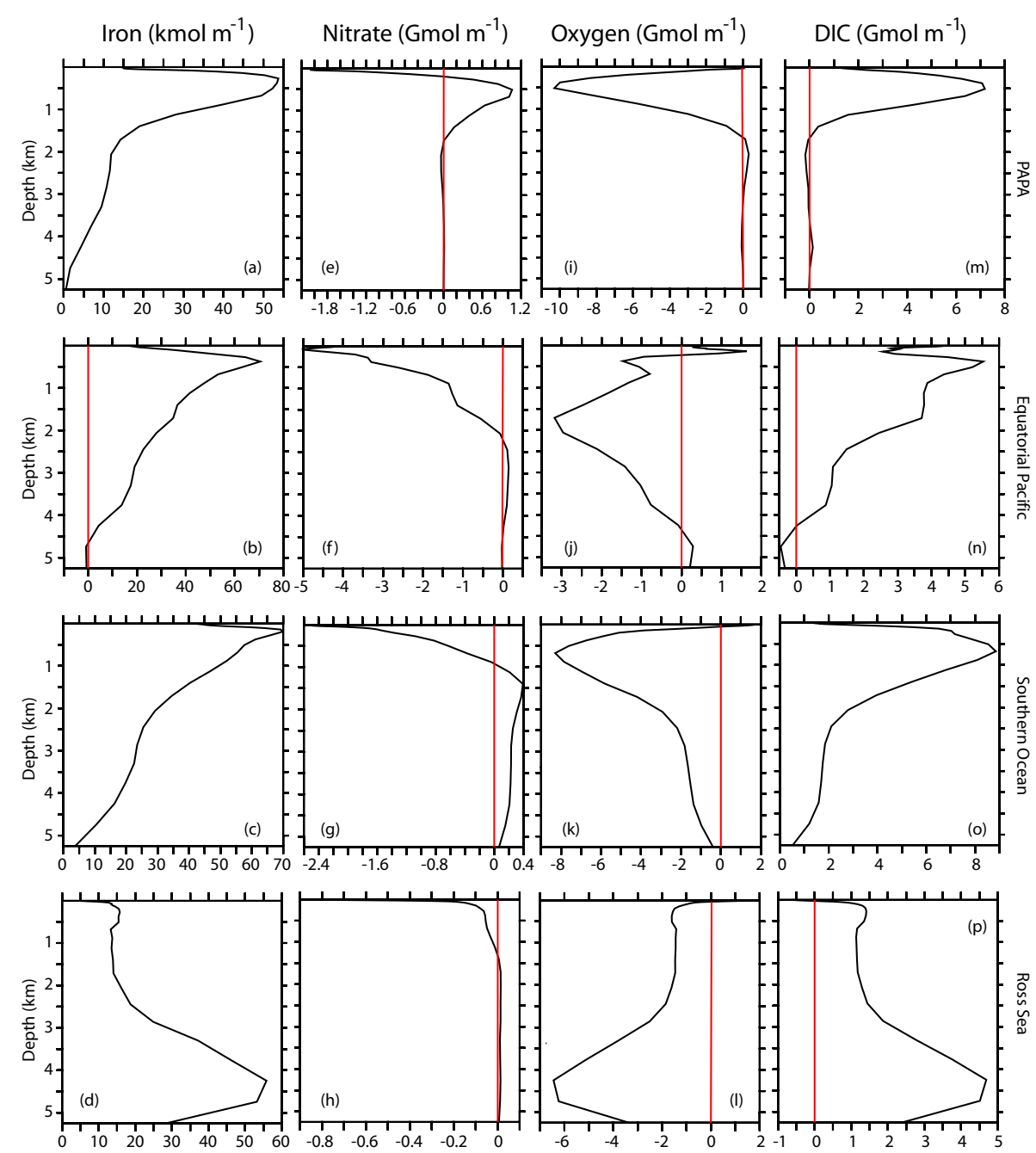

Fig. 6. Global horizontally integrated 100-year cumulative perturbation results of the 1200x iron fertilization scenarios plotted as a function of depth. The first column, (a to d), is the iron concentration perturbation in $\mathrm{kmol} \mathrm{m}^{-1}$; the second column, (e to h), is the nitrate concentration perturbation in $\mathrm{Gmol} \mathrm{m}^{-1}$; and the third column, (i to $\mathbf{l}$ ), is the oxygen concentration perturbation in $\mathrm{Gmol} \mathrm{m}^{-1}$. The first row of results is for PAPA, the second for the equatorial Pacific, the third for the Southern Ocean and the bottom row is the Ross Sea.

the vertically integrated horizontal distributions of nitrate and oxygen. As might be expected, Fig. 6 shows that the addition of iron increases the iron inventory at all locations, that the enhanced removal of nutrients from the surface ocean causes a downward displacement of the perturbation nitrate distribution (reduced in the upper ocean and increased at depth), and that there is an overall reduction in the oxygen inventory (except right near the surface due to photosynthetic production of oxygen at the Equatorial Pacific site).

Comparison of Figs. 6 and 7 shows that the nitrate surplus is largely a deep ocean phenomenon confined to the vicinity of the four sites, whereas the nitrate deficit is largely an upper ocean phenomenon with a widespread distribution. As a consequence of the widespread upper ocean nitrate reduction, the cumulative perturbation export production away from the fertilization sites is generally reduced in the subtropical gyre regions, which are already nitrate-limited in the control scenario (Fig. 7i-1), but have adequate light and iron (Fig. 1) such that the additional iron has no impact (cf. Gnanadesikan et al., 2003).

At year 100, the oxygen deficit in the fertilization scenarios is still largely confined to the vicinity of the four sites, which means the north Pacific for PAPA, the eastern tropical Pacific for the equatorial Pacific site, and the circumpolar region for the Southern Ocean and Ross Sea sites, though with some influence on northward flowing bottom waters in the Ross Sea case. In the particular case of the Equatorial Pacific, the reduction in oxygen is concentrated in the vast region of suboxia (defined as $\mathrm{O}_{2}<10 \mathrm{mmol} \mathrm{m}^{-3}$ ) of the eastern tropical Pacific shown in Fig. 2e. Reduced oxygen due to fertilization at this site thus causes an expansion of the suboxic zone and an increase in the water column loss of 


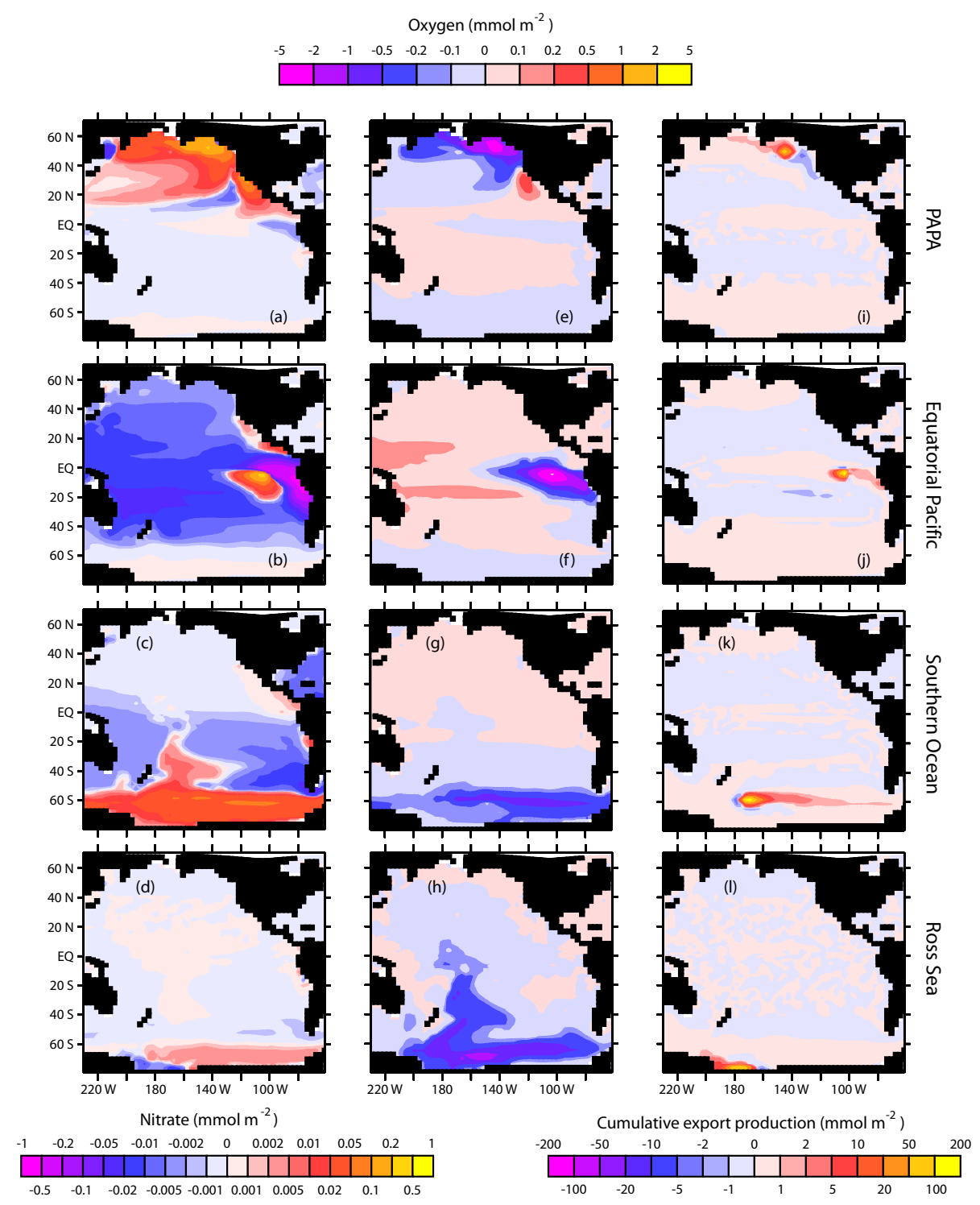

Fig. 7. Perturbation maps of the 1200x iron fertilization scenarios at year 100. The first column, (a-d), shows the nitrate concentration perturbation in $\mathrm{mmol} \mathrm{m}^{-2}$ integrated vertically from $98 \mathrm{~m}$ depth to the bottom; the second column, (e-h), is the oxygen concentration perturbation in $\mathrm{mol} \mathrm{m} \mathrm{m}^{-2}$ integrated vertically from $98 \mathrm{~m}$ depth to the bottom; and the third column, (i-l), is cumulative export production across $98 \mathrm{~m}$ integrated over the 100 years of the simulation in $\mathrm{mmol} \mathrm{m}^{-2}$. The first row of results is for PAPA, the second for the equatorial Pacific, the third for the Southern Ocean and the bottom row is the Ross Sea.

Table 4. Global perturbation nitrogen budget for each of the iron fertilization scenarios in the 1200x case.

\begin{tabular}{lrrrr}
\hline \multirow{2}{*}{ Field } & \multicolumn{4}{c}{ N change over 100 years (Tmol/100 yr) } \\
& PAPA & Equatorial Pacific & Southern Ocean & Ross Sea \\
\hline $\mathrm{N}_{2}$ fixation & 0.195 & 0.837 & 0.125 & 0.009 \\
Sediment denitrification & -0.000 & -0.003 & -0.003 & 0.016 \\
Water column denitrification & -0.337 & 4.827 & -0.269 & -0.014 \\
$\Delta$ fixed $\mathrm{N}$ & 0.532 & -3.987 & 0.396 & -0.007 \\
$\left(\Delta \mathrm{NO}_{3}\right)$ & $(0.514)$ & $(-3.954)$ & $(0.259)$ & $(-0.033)$ \\
\hline
\end{tabular}


nitrate by denitrification (which in this model is turned on when oxygen is $<5 \mathrm{mmol} \mathrm{m}^{-3}$ ). The cumulative 100 year nitrogen budget given in Table 4 shows that denitrification resulting from iron fertilization at the Equatorial Pacific site totals almost $5 \mathrm{Tg}$ of $\mathrm{N}$ over 100 years. The large cumulative $\mathrm{N}_{2}$ fixation of $\sim 1 \mathrm{Tg} \mathrm{N}$ resulting from iron fertilization at this site is too small to counterbalance the denitrification, and the cumulative loss of fixed nitrogen (mostly in the form of nitrate) comes to almost $4 \mathrm{Tg} \mathrm{N}$ over the 100 year period. This overall response of enhanced denitrification exceeding enhancement of nitrogen fixation is unexpected. It goes in the opposite direction from the feedback found by Moore and Doney (2007) in their model study, which showed an increase in the marine fixed nitrogen inventory, albeit with global iron stress relief. The influence of iron fertilization on the nitrate inventory at the other three sites is more modest. All three show a slight increase of oxygen in the eastern tropical Pacific, and a corresponding decrease in water column denitrification. The change in sedimentary denitrification is very small at all sites except the Ross Sea where the increased productivity coupled together with the shallow depth of this location (545 m, see Table 2), which means that a higher fraction of the exported organic matter reaches the sediments than at other sties, result in a fairly large increase in sedimentary denitrification. All three also show an increase of surface $\mathrm{N}_{2}$ fixation. Overall, PAPA and the Southern Ocean show a small increase in the nitrate inventory, while the Ross Sea is almost neutral due to the increase in sediment denitrification.

\subsection{Response of air-sea $\mathrm{CO}_{2}$ flux}

In this section, we follow the IFMIP protocols in showing only simulations with a fixed atmospheric $\mathrm{CO}_{2}$ at a preindustrial partial pressure of $278 \mu \mathrm{atm}$. In Sect. 4.2.1, we describe sensitivity studies that show how the results change when the atmospheric reservoir of $\mathrm{CO}_{2}$ is allowed to drop as iron fertilization removes $\mathrm{CO}_{2}$ (cf. Gnanadesikan et al., 2003).

A comparison of the air-sea fluxes from the $1 \mathrm{x}$ simulations in Fig. 8a with the export production in Fig. 5a shows that the peak in the air-sea flux occurs about a month after the peak in the export production. The $\mathrm{CO}_{2}$ uptake pulse extends over about 3 months at the Ross Sea site, 9 months at the PAPA and Southern Ocean sites, and 15 months at the Equatorial Pacific site. The Equatorial Pacific site best reflects the time scale of air-sea equilibration in a somewhat more stable situation where the DIC deficit generated by the iron fertilization lasts year around, whereas, as we shall show below, the other sites are more strongly influenced by seasonality, with the DIC deficit generated by the export pulse becoming extremely small in the wintertime. In particular, the surface DIC concentration at the Ross Sea site returns to its control wintertime value for 5 months of the year and only departs from it significantly for 3 to 4 months of the year.
A major feature of the annual perturbation atmospheric $\mathrm{CO}_{2}$ uptake shown in Fig. 8e to $\mathrm{h}$ is that the $\mathrm{CO}_{2}$ uptake by the ocean plummets into the negative range as soon as iron fertilization ends in the 1x and 10x scenarios, and that, unlike the export production, it drops lower and lower over time as the fertilization is continued over 100 years in the 100x and 1200x cases. The one exception to this behavior is the Ross Sea site which drops to zero but does not become negative in the $1 \mathrm{x}$ and $10 \mathrm{x}$ cases, and which remains nearly constant over time in the 100x and 1200x cases. The rebound effect of $\mathrm{CO}_{2}$ escaping back to the atmosphere upon cessation of fertilization that we find in the $1 \mathrm{x}$ and 10x cases at all the sites except the Ross Sea has been demonstrated in many of the nutrient depletion scenarios (e.g., Sarmiento and Orr, 1991), and was also found in the ecosystem/model simulation of Aumont and Bopp (2006). However, cessation of fertilization in nutrient depletion scenarios occurs by immediately allowing restoration of surface nutrients back to their normal control values, and is thus likely to exaggerate the return flux of sequestered $\mathrm{CO}_{2}$; and the model of Aumont and Bopp (2006) has an interactive atmosphere and would therefore have a significant contribution to the return flux due to lowered $\mathrm{CO}_{2}$ in the atmosphere. Here we find that the rebound effect occurs even with fixed atmospheric $\mathrm{CO}_{2}$ in our $1 \mathrm{x}$ and 10x simulations (Fig. 8e and f). Furthermore, even the continued addition of iron in the 100x and 1200x cases is not able to prevent the annual uptake of $\mathrm{CO}_{2}$ from the atmosphere from dropping over time (with the exception of the Ross Sea site; Figs. 8g and h) despite the fact that the magnitude of the export production remains high (except at the Equatorial Pacific site; Fig. $5 \mathrm{~g}$ and h). This drop off has a major negative impact on the efficiency of iron fertilization, as we shall see in Sect. 4.1, where we will also discuss why the Ross Sea site behaves so differently from the other sites.

Another interesting result in the 1x, 10x, and 100x atmospheric $\mathrm{CO}_{2}$ uptake scenarios is that the cumulative Ross Sea site uptake is much greater than the Southern Ocean uptake (Fig. 8i to k and Table 5a) despite the perturbation export production of these two being virtually identical in the 10x and 100x simulations and very similar in the $1 \mathrm{x}$ case (Fig. 5i to k). The reason for this will be discussed in Sect. 4.1. The relative behavior of the Ross Sea and Southern Ocean sites reverses in the 1200x scenario due to the previously discussed wintertime shut down at the Ross Sea site.

\section{Discussion}

We begin with a discussion of the efficiency of iron fertilization (the cumulative atmospheric $\mathrm{CO}_{2}$ uptake divided by the cumulative iron addition as in Eq. 1) and the processes that determine it, followed by a discussion of the sensitivity studies that we carried out. 


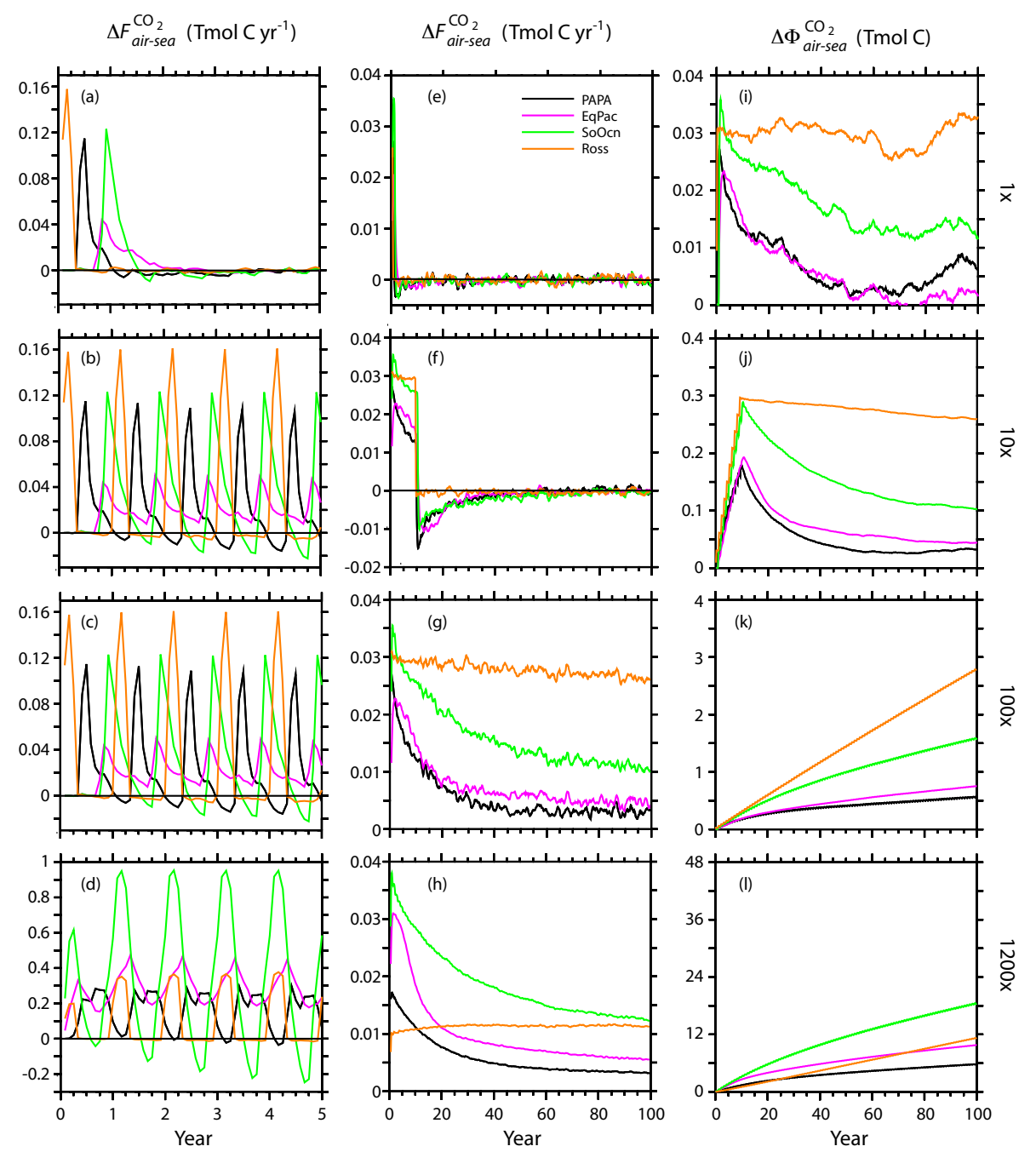

Fig. 8. Results of the iron fertilization scenarios plotted as a function of time for: (a-d), annual uptake of $\mathrm{CO}_{2}$ plotted month by month for the first 5 years, $\Delta F_{\text {air-sea }}^{\mathrm{CO}_{2}}$; (e-h), annual uptake of $\mathrm{CO}_{2}$ from the atmosphere for 100 years, $\Delta F_{\text {air-sea }}^{\mathrm{CO}_{2}}$; (i-l), cumulative $\mathrm{CO}_{2}$ uptake from the atmosphere, $\Delta \Phi_{\text {air-sea }}^{\mathrm{CO}_{2}}$. The first row of results is for the 1x scenarios, the second for the 10x scenarios, the third for the 100x scenarios, and the bottom row is for the $1200 \mathrm{x}$ scenarios.

\subsection{Efficiency of fertilization}

Figure 9 shows the overall fertilization efficiency and its components that we defined in Eq. (1) and (2). From Fig. 9a to $\mathrm{c}$ and Table $5 \mathrm{~b}$, we see that by far the most efficient fertilization site is the Ross Sea, except in the 1200x case, where the Southern Ocean site becomes dominant. The Ross Sea in particular has a very high $\mathrm{CO}_{2}$ uptake to iron fertilization mole ratio of 150000 to 188000 for the $1 \mathrm{x}, 10 \mathrm{x}$, and 100x simulations for the entire period of the fertilization. This is very similar to the efficiencies obtained by Arrigo and Tagliabue (2005) in their much higher resolution regional model of the Ross Sea, although the comparison must be made with care since they calculated their efficiency over a local area (their Box A), whereas we calculated ours over the entire world. The Ross Sea efficiency plunges well below the other sites for the first $\sim 50$ years of the $1200 x$ continuous fertilization scenario due to the ineffectiveness of iron fertilization during the polar winter. Next in efficiency is the Southern Ocean, which is about half as efficient as the Ross Sea in the 100x case and less than that in the $1 \mathrm{x}$ and $10 \mathrm{x}$ cases, but exceeds the Ross Sea in the 1200x case. Both PAPA and the Equatorial Pacific site are by far the least efficient, with C:Fe ratios that are about half of the Southern Ocean site for the $10 x, 100 x$, and 1200x scenarios. Because the efficiency in the $1 \mathrm{x}$ scenario for all four sites is extremely noisy due to the small size of the iron fertilization perturbation relative to the background variability in this scenario, it has not been included in Fig. 9. 

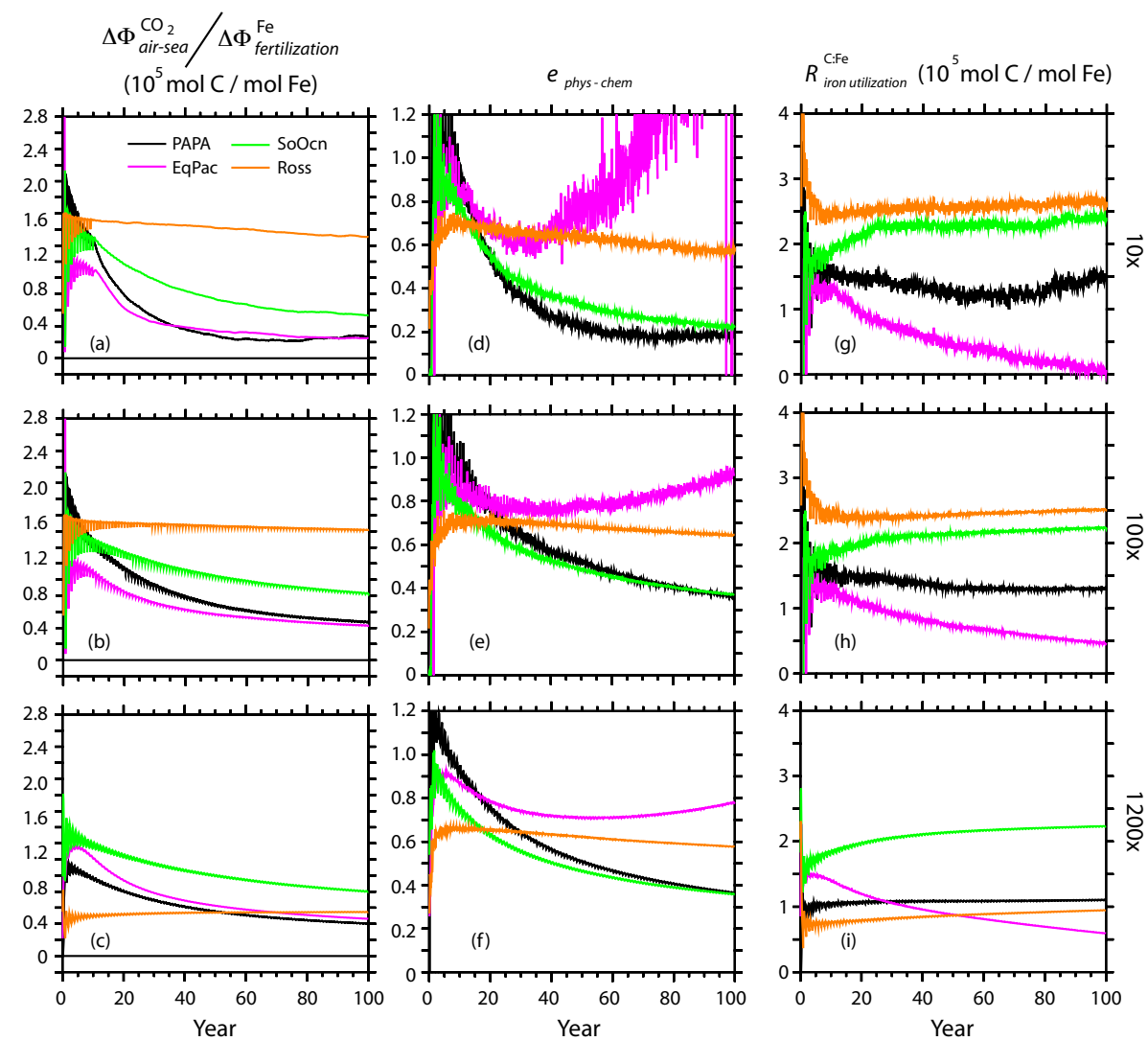

Fig. 9. Results from the iron fertilization scenarios plotted as a function of time from 0 to 100 years of (a-c), the efficiency of $\mathrm{CO}_{2}$ uptake

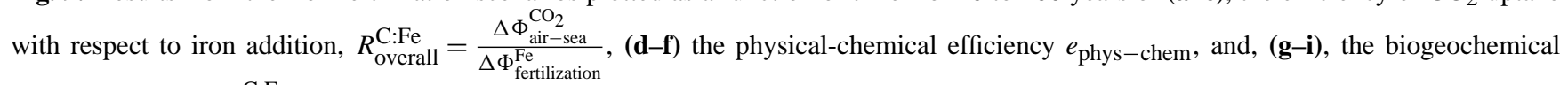
response function, $R_{\text {iron utilization }}^{\mathrm{C} \text {.Fe }}$ The first row of results is for the $10 \mathrm{x}$ scenarios, the second for the $100 \mathrm{x}$ scenarios, and the bottom row is for the $1200 x$ scenarios.

Table 5. Effectiveness and efficiency of $\mathrm{CO}_{2}$ uptake from the atmosphere.

(a) Effectiveness = cumulative $\mathrm{CO}_{2}$ uptake $(\mathrm{Tg} \mathrm{C})$

\begin{tabular}{|c|c|c|c|c|c|c|c|c|c|c|c|c|}
\hline & \multicolumn{4}{|c|}{ Year 10} & \multicolumn{4}{|c|}{ Year 50} & \multicolumn{4}{|c|}{ Year 100} \\
\hline & PAPA & $\mathrm{Eq} \mathrm{Pac}$ & S. Ocean & Ross Sea & PAPA & $\mathrm{Eq} \mathrm{Pac}$ & S. Ocean & Ross Sea & PAPA & $\mathrm{Eq} \mathrm{Pac}$ & S. Ocean & Ross Sea \\
\hline $1 x$ & 0.16 & 0.17 & 0.30 & 0.35 & 0.03 & 0.04 & 0.18 & 0.34 & 0.08 & 0.03 & 0.14 & 0.39 \\
\hline $10 \mathrm{x}$ & 2.13 & 2.25 & 3.33 & 3.55 & 0.40 & 0.71 & 1.71 & 3.35 & 0.38 & 0.52 & 1.24 & 3.12 \\
\hline $100 x$ & 2.13 & 2.25 & 3.33 & 3.55 & 4.93 & 5.98 & 12.1 & 17.2 & 6.76 & 9.03 & 19.2 & 33.5 \\
\hline $1200 x$ & 16.8 & 30.8 & 37.4 & 12.1 & 47.8 & 79.1 & 138. & 66.8 & 69.4 & 117. & 222. & 136. \\
\hline
\end{tabular}

(b) Efficiency $=\mathrm{C}: \mathrm{Fe}$ mol ratio of $\mathrm{CO}_{2}$ uptake to iron addition $\left(\mathrm{x} 10^{5}\right)$

\begin{tabular}{l|cccc|cccc|cccc}
\hline & \multicolumn{9}{|c}{ Year 10 } & \multicolumn{3}{c}{ Year 50 } \\
& PAPA & Eq Pac & S. Ocean & Ross Sea & PAPA & Eq Pac & S. Ocean & Ross Sea & PAPA & Eq Pac & S. Ocean & Ross Sea \\
$1 \mathrm{x}$ & 1.10 & 0.83 & 1.32 & 1.72 & 0.20 & 0.17 & 0.77 & 1.66 & 0.52 & 0.14 & 0.62 & 1.88 \\
$10 \mathrm{x}$ & 1.49 & 1.06 & 1.44 & 1.70 & 0.28 & 0.34 & 0.74 & 1.61 & 0.26 & 0.25 & 0.54 & 1.50 \\
$100 \mathrm{x}$ & 1.49 & 1.06 & 1.44 & 1.70 & 0.69 & 0.57 & 1.04 & 1.65 & 0.47 & 0.43 & 0.83 & 1.61 \\
$1200 \mathrm{x}$ & 0.98 & 1.21 & 1.35 & 0.49 & 0.55 & 0.62 & 1.00 & 0.54 & 0.40 & 0.46 & 0.80 & 0.55 \\
\hline
\end{tabular}



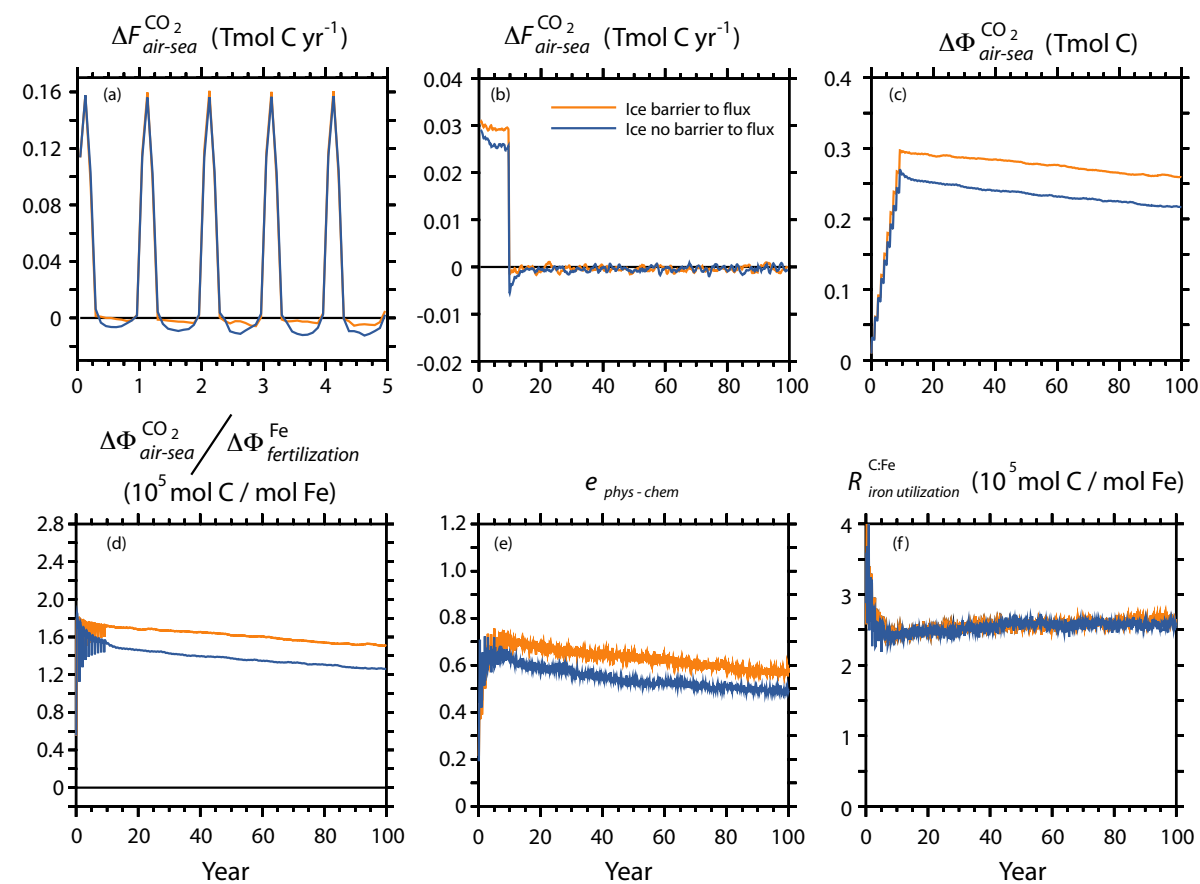

Fig. 10. Results from the 10x iron fertilization scenario at the Ross Sea site calculated the standard way with an ice barrier to $\mathrm{CO}_{2}$ flux, and also with gas exchange allowed across the ice barrier. The figure shows: (a) the annual uptake of $\mathrm{CO}_{2}$ plotted month by month for the first 5 years, $\Delta F_{\text {air-sea }}^{\mathrm{CO}_{2}}$; (b) the annual uptake of $\mathrm{CO}_{2}$ from the atmosphere for 100 years, $\Delta F_{\text {air-sea }}^{\mathrm{CO}_{2}}$; (c) the cumulative $\mathrm{CO}_{2}$ uptake from the atmosphere, $\Delta \Phi_{\text {air-sea }}^{\mathrm{CO}_{2}}$; (d) the efficiency of $\mathrm{CO}_{2}$ uptake with respect to iron addition, $R_{\text {overall }}^{\mathrm{C}: \mathrm{Fe}}=\frac{\Delta \Phi_{\text {air-sea }}^{\mathrm{CO}_{2}}}{\Delta \Phi_{\text {fertilization }}^{\mathrm{Fe}}} ;(\mathbf{e})$ the physical-chemical uptake efficiency $e_{\text {phys-chem }}$; and, (f) the biogeochemical response function, $R_{\text {ironutilization }}^{\mathrm{C} F e}$

What accounts for the differences in responses to the iron addition between the four regions illustrated in Fig. 9a to c? To answer this question, we find it useful to analyze the results in terms of the physical-chemical response function $e_{\text {phys-chem }}$ and the biogeochemical response function $R_{\text {iron additionn. }}^{\mathrm{C} \text { :Fe }}$. Figures $9 \mathrm{~d}$ to i show the results of this analysis for the 10x, 100x, and 1200x simulations. The first result we draw attention to is that $e_{\text {phys-chem }}$ goes above 1 during approximately the first decade at the PAPA, Equatorial Pacific, and Southern Ocean sites (Fig. 9d to f). These high values of $e_{\text {phys-chem }}$ during the first decade are due to an early accumulation of dissolved organic carbon (DOC), after which it levels off. The accumulation of DOC results in a removal of $\mathrm{CO}_{2}$ from the atmosphere that is not matched by a corresponding export of $\mathrm{POC}$ and $\mathrm{CaCO}_{3}$. The accumulation of DOC also causes a reduction of $R_{\text {iron addition }}^{\mathrm{C} \text { :Fe }}$ over the first decade (Fig. 9 g to i).

The second result we draw attention to is that the biogeochemical response function in Fig. 9g to $\mathrm{i}$ is quite different at the Equatorial Pacific site than at any of the others. The Equatorial Pacific site has less nitrate in the control scenario to start with (see Fig. 3f), and in addition, as discussed in Sect. 3.2, there is loss of nitrate by denitrification due to an increase in the volume of suboxic waters. The nitrate loss due to fertilization at the Equatorial Pacific site already begins to lower the biological export production within one to two decades after the initiation of fertilization (see Fig. 5), and is the principal reason that the Equatorial Pacific site has such a low efficiency in the 10x, and 100x cases shown in Fig. 9a and b. The only reason that the Equatorial Pacific site has a higher efficiency than PAPA and the Ross Sea for the first several decades of the continuous fertilization 1200x case of Fig. $9 \mathrm{c}$ is because of the reduced effectiveness of the iron addition at PAPA and the Ross Sea during the wintertime. The anomalous decrease of the perturbation carbon export also causes the physical-chemical response function shown in Fig. 9d to f, to sweep upwards after first decreasing like the other fertilization sites. This behavior is due to the unusual biological response, namely denitrification, and not to the biological, physical, and chemical processes we are trying to diagnose with the physical-chemical response function. We thus will not comment any further on the Equatorial Pacific site results in Fig. 9.

Turning to the other three sites, we see first that the Ross Sea and Southern Ocean are similar to each other in terms of the biogeochemical response function (Fig. $9 \mathrm{~g}$ and $\mathrm{h}$ ), except when the fertilization is extended to include the Austral winter in the 1200x case (Fig. 9i). In this latter case the wintertime deep mixing and lack of light in the Ross Sea (Fig. 3) 


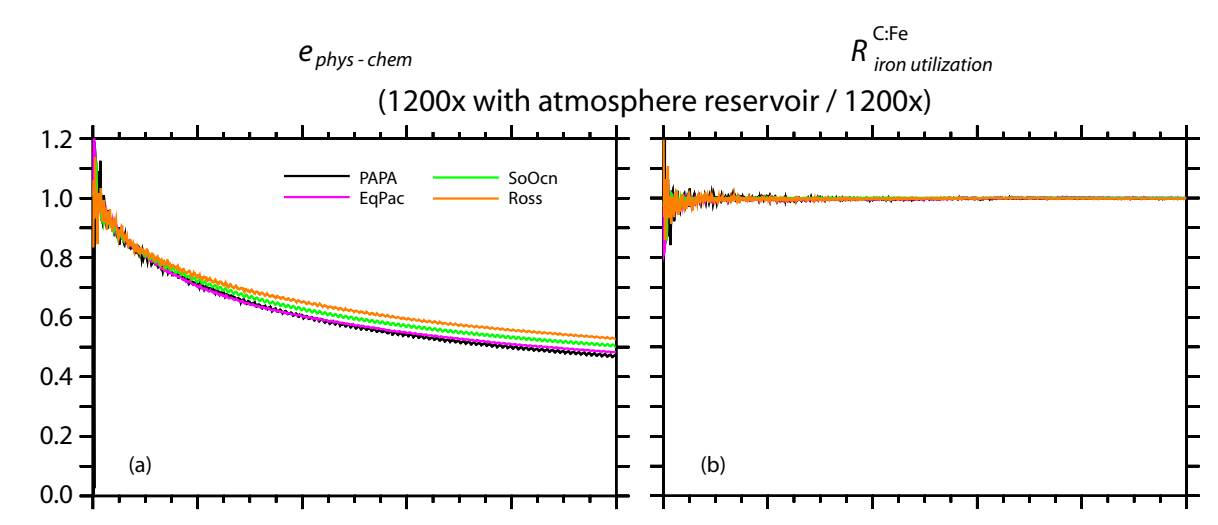

(1200x with iron lost / 1200x)

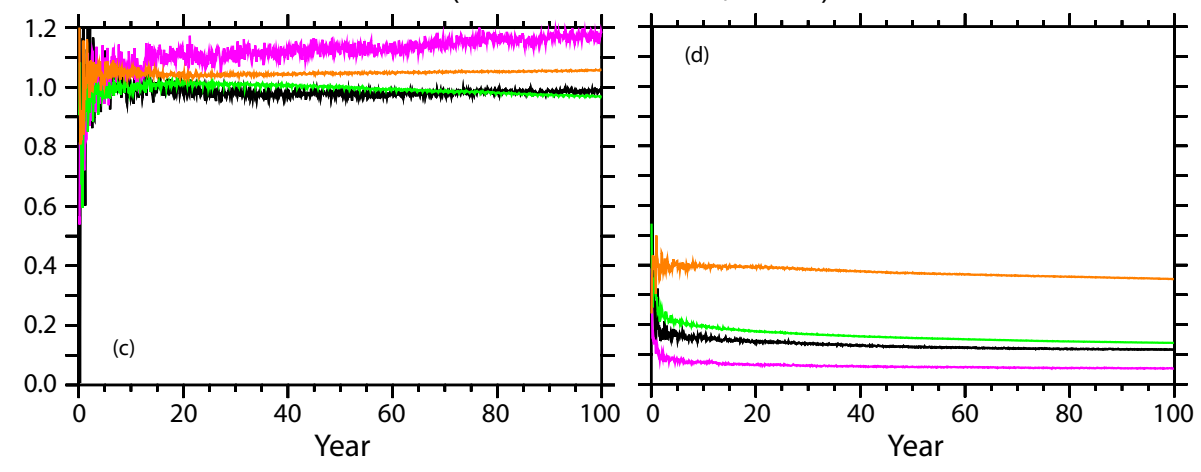

Fig. 11. Sensitivity studies of factors contributing to the efficiency of the 1200x simulations. Panels (a) and (b) examine the sensitivity to the inclusion of an atmospheric reservoir, and Panels (c) and (d) examine the sensitivity to the retention of iron, all plotted as a function of time from 0 to 100 years. The first row shows the uptake efficiency $e_{\text {phys }- \text { chem }}$ and the overall C:Fe iron utilization ratio, $R_{\text {ironaddition }}^{\mathrm{C} F \mathrm{~F}}$ for the simulation with a variable atmosphere divided by the corresponding quantity in the standard $1200 \mathrm{x}$ simulation. The second row shows $e_{\text {phys-chem }}$ and $R_{\text {ironaddition }}^{\mathrm{C}: \mathrm{Fe}}$ for the simulation with no iron remineralization divided by the corresponding quantity in the standard $1200 \mathrm{x}$ simulation.

causes its biogeochemical response function to plummet to the bottom of the group. Where the Ross Sea clearly stands out above the Southern Ocean (as well as PAPA) is in its high physical-chemical response function (Fig. 9d to f). One reason it has such a high physical-chemical response function is that the Ross Sea site is covered by seasonal ice, which prevents sequestered $\mathrm{CO}_{2}$ from escaping during the wintertime. A 10x simulation in which sea ice was allowed to be completely porous to gas fluxes shows a loss of $\mathrm{CO}_{2}$ in winter (Fig. 10a), a rebound loss of excess $\mathrm{CO}_{2}$ from the ocean when iron fertilization is terminated after 10 years (Fig. 10b), a lower cumulative $\mathrm{CO}_{2}$ uptake overall (Fig. 10c), and a reduced physical-chemical efficiency (Fig. 10e). However, even with porous ice, the Ross Sea site still has a higher physical-chemical efficiency than the Southern Ocean and PAPA sites, which we believe is due mostly to the fact that the excess DIC is stored primarily in the inaccessible deep and bottom waters of the ocean (Fig. 6p) rather than in the thermocline and intermediate waters as at the other sites (Fig. 6m to o). The Ross Sea site has a bottom depth of $545 \mathrm{~m}$ in the model, so it is not the depth of remineralization that is putting the DIC excess in to the deep and bottom waters, but rather the lateral transport of water from the Ross Sea site down into the abyss. The excess DIC is reflected in reduced $\mathrm{O}_{2}$ (Fig. 61) and we see in Fig. 7h that the oxygen deficit in the deep and bottom waters is carried towards the east in the circumpolar region and towards the north into the Pacific. We also considered whether the shallower summertime mixed layer and euphotic zone of the Ross Sea site (Fig. 3d) might play a role as suggested by the Jin et al. (2008) sensitivity studies, which showed that the physical-chemical response function depends on the depth at which the enhanced formation of organic matter occurs in response to iron addition. However, while there may be some contribution from this mechanism, the fact that the physical-chemical efficiency is lower at the Ross Sea site than at the other sites during the first decade and longer (Fig. 9d to f) does not support this interpretation.

By contrast with the Ross Sea, the Southern Ocean and PAPA sites have similar physical-chemical response functions (Fig. 9d to f). The reason that the Southern Ocean has much higher iron fertilization efficiency than PAPA is because of the biogeochemical response function, which is far greater at the Southern Ocean site than at PAPA (Fig. 9g to i) due to the higher initial nutrient concentrations at this location (Fig. 3). 
Table 6. Atmospheric reservoir effect. The table shows the ratio of a model with an atmospheric reservoir to the same simulation without a reservoir. The Equatorial Pacific 1x result is not trustworthy because the cumulative uptake is near 0 at 100 years.

\begin{tabular}{lcccccccc}
\hline Iron flux multiple & \multicolumn{2}{c}{$1 \mathrm{x}$} & \multicolumn{2}{c}{$10 \mathrm{x}$} & \multicolumn{2}{c}{$100 \mathrm{x}$} & \multicolumn{2}{c}{$1200 \mathrm{x}$} \\
Time of analysis & $10 \mathrm{yr}$ & $100 \mathrm{yr}$ & $10 \mathrm{yr}$ & $100 \mathrm{yr}$ & $10 \mathrm{yr}$ & $100 \mathrm{yr}$ & $10 \mathrm{yr}$ & $100 \mathrm{yr}$ \\
\hline PAPA & 0.58 & 0.24 & 0.79 & 0.26 & 0.79 & 0.45 & 0.80 & 0.47 \\
Equatorial Pacific & 0.59 & $(1.87)$ & 0.81 & 0.27 & 0.81 & 0.48 & 0.80 & 0.48 \\
Southern Ocean & 0.67 & 0.30 & 0.81 & 0.31 & 0.81 & 0.50 & 0.80 & 0.51 \\
Ross Sea & 0.69 & 0.31 & 0.80 & 0.40 & 0.80 & 0.53 & 0.81 & 0.53 \\
\hline
\end{tabular}

\subsection{Model sensitivity studies}

Four sets of model sensitivity studies were carried out as part of our study.

\subsubsection{Coupling to an atmospheric reservoir}

The IFMIP protocol specified a fixed atmospheric $\mathrm{CO}_{2}$ concentration following the design of the original study by Dutkiewicz et al. (2006). However, we expect that as $\mathrm{CO}_{2}$ is removed from the atmosphere by iron fertilization, this will lead to a reversal in the global air-sea $\mathrm{CO}_{2}$ gradient relative to what it would have been without the $\mathrm{CO}_{2}$ removal. Much of the $\mathrm{CO}_{2}$ taken up locally in the iron fertilization region will thus escape back to the atmosphere in the rest of the ocean, as demonstrated by Gnanadesikan et al. (2003) (cf. also Oschlies, 2009). In order to examine the magnitude of this feedback, we carried out a set of sensitivity studies in which the 1200x simulations were repeated but in an ocean model that was coupled to an atmospheric reservoir. The $\mathrm{CO}_{2}$ in the atmospheric reservoir was fixed at $278 \mathrm{ppm}$ in the model spin-up, and then allowed to vary in both the control and iron fertilization simulations for the period of the iron fertilization. We leave for future simulations the inclusion of secondary effects that will also impact the iron fertilization efficiency, including a more realistic atmospheric $\mathrm{CO}_{2}$ trajectory driven by fossil fuel $\mathrm{CO}_{2}$ emissions and terrestrial sources and sinks (cf. Joos et al., 1991; and Oschlies, 2009) as well as the impact of climate on the terrestrial and oceanic sources and sinks.

Figure 11a and Table 6 show that including a variable atmosphere allows $20 \%$ of the $\mathrm{CO}_{2}$ taken up in the fixed atmosphere 1200x simulation to escape after only 10 years, and $\sim 50 \%$ after 100 years. The $100 x$ fertilization is very similar, but for the shorter-term $1 \mathrm{x}$ and $10 \mathrm{x}$ cases, the reduction of $\mathrm{CO}_{2}$ uptake is more drastic, getting as high as $76 \%$ after 100 years in the PAPA $1 \mathrm{x}$ case. This is clearly a major effect that cannot be ignored in model simulations. Note from Fig. 11b that the biogeochemical response function is identical to that of the 1200x simulation with a fixed atmosphere, as would be expected.

\subsubsection{Iron retention}

A 1200x simulation was carried out in which the added iron was assumed to be scavenged from the ocean permanently once it is taken up by biology. We refer to this as the "iron added and removed" simulation. Our intention was to examine the explanation of Gnanadesikan et al. (2003) for the ratio of $\sim 1: 20$ in $\mathrm{CO}_{2}$ uptake efficiency ( $2 \%$ versus $42 \%$ ) between the simulations that they characterized as behaving like an iron added and removed scenario, and those they characterized as behaving essentially like iron added and retained simulations. Note: since the Gnanadesikan et al. (2003) model did not include an explicit parameterization of iron cycling, their equivalent to our definition of the iron fertilization efficiency given in Eq. (1) replaces the iron addition term in the denominator with the carbon export during the one month of fertilization, $\Delta \Phi_{\text {export }}^{\mathrm{POC} \& \mathrm{CaCO}_{3}}$ (fertilization period), i.e.,

$$
\frac{\Delta \Phi_{\text {air-sea }}^{\mathrm{CO}_{2}}}{\Delta \Phi_{\text {export }}^{\mathrm{POC} \& \mathrm{CaCO}_{3}}(\text { fertilization period })}
$$

The carbon export during the fertilization period is taken by them to be representative of the initial iron addition. The results from our simulations that we show below are based on our original definitions in (1) and (2).

Figure 11c and d show the ratio of our 1200x iron added and lost scenario to our standard 1200x scenario for the physical-chemical response function and our biogeochemical efficiency. Figure 12 shows the efficiency of iron retention in the standard 1200x scenario. At the end of 100 years, $\sim 60 \%$ of the added iron is still in the ocean, whereas in the iron added and lost scenario, only the most recently added iron is present. Figure 11c shows that our iron added and lost simulations have almost the same physical-chemical response function as the standard 1200x simulations at all the sites. The EqPac site is a little high because the iron added and lost simulation does not have as much denitrification as the standard 1200x scenario. The biogeochemical efficiency ratios in Fig. 11d confirm that it is the continued ability of retained iron to maintain the flux of carbon out of the surface at a high level that is principally responsible for the much higher efficiency of the standard 1200x scenario over the iron added and removed scenario. Indeed, the EqPac site has 1/20th as 


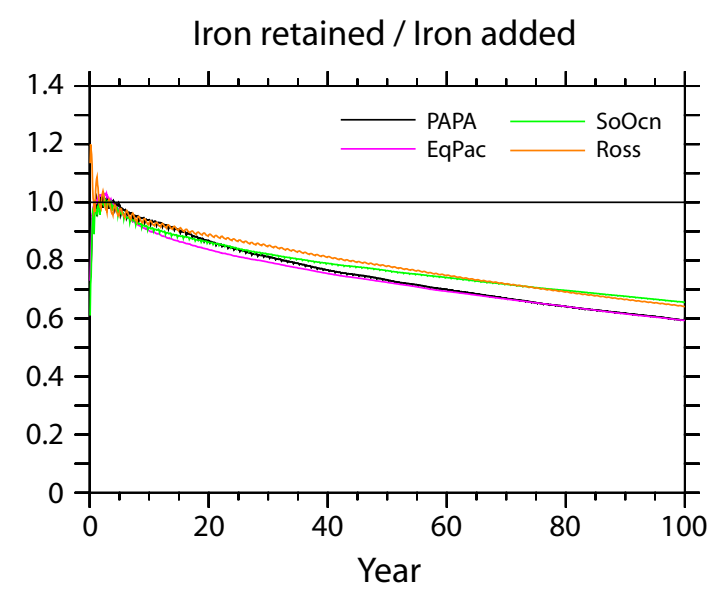

Fig. 12. The ratio of iron retained in the ocean with respect to the iron added in the 1200x scenario. Despite the continuous addition of iron in this model, the scavenging of iron out of the ocean is such that only $\sim 60 \%$ of the iron is present at the end of the simulation.

much $\mathrm{CO}_{2}$ removal from the atmosphere in the iron added and removed simulation than in the standard 1200x scenario, which is consistent with the difference that Gnanadesikan et al. (2003) saw in their simulations. Jin et al. (2008) suggest in their analysis that at least part of the difference in the two model simulations of Gnanadesikan et al. (2003) appears to be due to an inadvertent effect of the way they designed their models, in which the iron added and retained scenario is actually removing carbon from the entire euphotic zone, whereas the iron added and removed scenario is removing carbon only from the base of the euphotic zone, but our results support Gnanadesikan et al. (2003) in their suggestion that most of the effect is due to the assumptions that were made regarding the role of iron cycling (i.e., whether iron is added and removed versus whether it is added and retained).

\subsubsection{Alternate growth formulation}

One of the limitations of this model's formulation of iron limitation of phytoplankton growth was the need to utilize elevated values of the maximum growth rate $P_{\mathrm{C}_{\max }}$ (see Supplementary Material) compared to observations of phytoplankton growth under ideal conditions. In order to examine how the results might change with a more realistic maximum growth rate, we carried out sensitivity studies using a Liebig formulation for the dependence of phytoplankton growth rate on the chlorophyll to carbon ratio (see Supplementary Material) and lower maximum zero-temperature-normalized growth rates of $0.98 \mathrm{~d}^{-1}$ as observed in the SEEDS experiment for Chaetoceros debilis (Tsuda et al., 2003). This modification resulted in only a modest $1-2 \%$ change in the iron fertilization $\mathrm{CO}_{2}$ uptake relative to the base formulation.
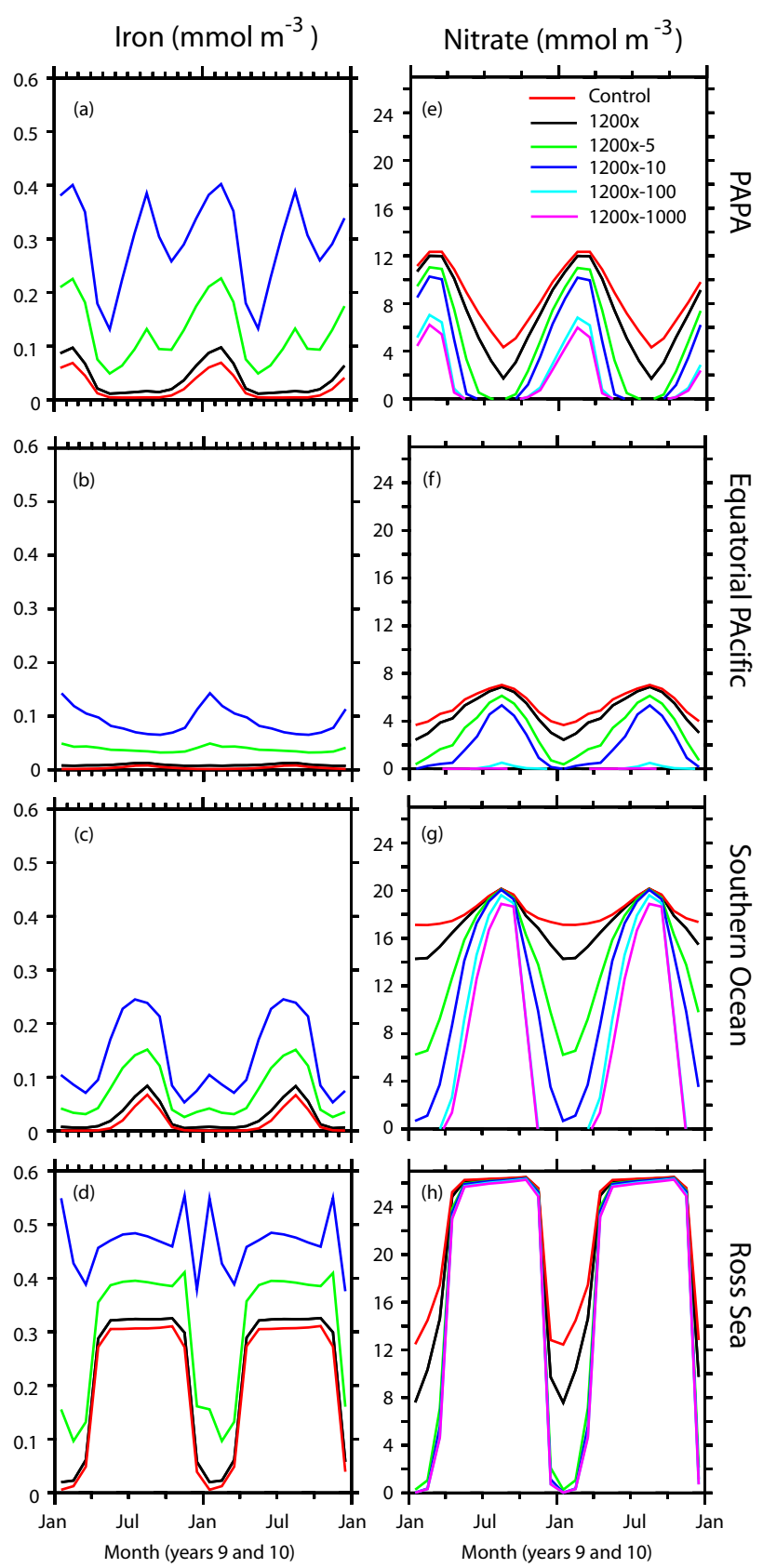

Fig. 13. Mean iron and nitrate in the top $10 \mathrm{~m}$ of the four fertilization sites after 10 years of constant fertilization with increasing additions of iron expressed here as a multiple of the standard $1200 \mathrm{x}$ scenario. The $1200 x-100$ and 1200x-1000 iron concentration profiles are off-scale. Note that the mean surface nitrate concentration stabilizes after $\sim 4$ years of continuous fertilization so the 10 year concentration is pretty much already at steady state for the given fertilization scenario. 


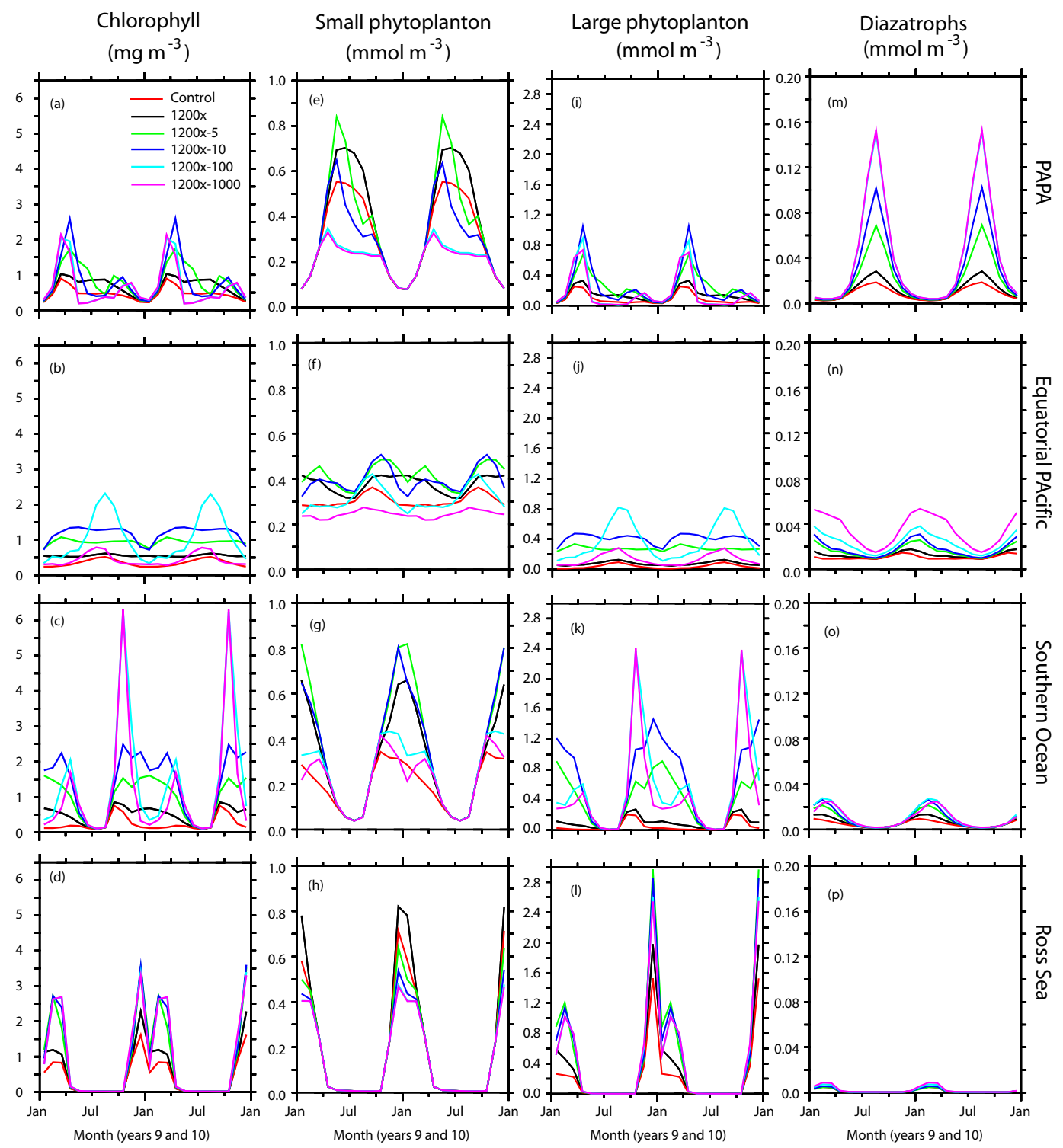

Fig. 14. Mean chlorophyll, and nitrogen in small phytoplankton, large phytoplankton, and diazotrophs in the top $10 \mathrm{~m}$ of the four fertilization sites after 10 years of constant fertilization with increasing additions of iron expressed here as a multiple of the standard 1200x scenario.

\subsubsection{Amount of iron added}

The per unit area iron flux of $0.02 \mathrm{mmol} \mathrm{m}^{2} \mathrm{yr}^{-1}$ in the standard 1200x simulation was chosen by Dutkiewicz et al. (2006) as representative of the background aeolian flux in their model, which ranges from a low of 0.001 to $0.5 \mathrm{mmol} \mathrm{m}^{-2} \mathrm{yr}^{-1}$. In none of the $1200 \mathrm{x}$ simulations was this aeolian flux sufficient to bring the iron concentration even close to the half-saturation constant of $0.3 \mu \mathrm{mol} \mathrm{m}{ }^{-3}$ for uptake of iron by large phytoplankton, which dominate iron fertilized blooms (Fig. 13a to d); nor was it sufficient to deplete surface nutrients even at the time of the nutrient minimum (see Fig. 13e to h). We carried out sensitivity studies with $1,5,10,100$, and 1000 times as much iron flux as in the 1200x control simulation (which we refer to as 1200x, $1200 x-5,1200 x-10,1200 x-100,1200 x-1000$ respectively) in order to determine how far we could go towards depleting the nutrients before something else became limiting. As we see in Fig. 13a to d, it is only in the 1200x-100 scenario (off scale in the figure) that the iron concentration climbs well above the large phytoplankton half saturation constant, but three of the four sites are nearly depleted in nitrate by the time the iron flux is increased by only 5 times the $1200 x$ case, and the Southern Ocean becomes depleted with an iron flux that is somewhere between 10 and 100 times the 1200x case (Fig. 13e to h). Note, however, that, except at the Equatorial Pacific site, and to a lesser extent at the PAPA site, this depletion of nutrients can only be accomplished at the time of 
the nutrient minimum. Because of the seasonality of the light supply and mixed layer depth, the nutrient concentration at the time of the nutrient maximum at the other sites is almost unaffected by the iron flux.

The ability of our model to completely draw down nitrate during the summertime nutrient minimum in the Southern Ocean is in contradiction to the similar analyses of Mongin et al. (2007), and Aumont and Bopp (2006), in both of which cases the model became light limited. Dutkiewicz et al. (2006) also find greater light sensitivity than iron sensitivity in their model. The differences between all these models are complex and subtle. What we can say about our model is that it has a relatively high half-saturation constant for the dependence of large phytoplankton (which dominate iron fertilized blooms) on iron, $0.3 \mu \mathrm{mol} \mathrm{m}{ }^{-3}$. This means that our model will in general be more sensitive to additional iron. Moreover, in our model the sensitivity to light is itself dependent on iron because additional iron allows for more chlorophyll synthesis, which greatly lowers the light sensitivity under iron replete conditions. For example, the half-saturation light level at the Southern Ocean site is only $\sim 3 \mathrm{~W} \mathrm{~m}^{-2}$ for iron-replete conditions as compared with the fixed value of $20 \mathrm{~W} \mathrm{~m}^{-2}$ used by Dutkiewicz et al. (2006) (though for iron concentrations of $0.1 \mu \mathrm{mol} \mathrm{m}{ }^{-3}$ our halfsaturation light level is closer to $12 \mathrm{~W} \mathrm{~m}^{-2}$ ). The treatment of iron-light colimitation in many models such as those of Mongin et al. (2007) gives increased limitation under conditions of increased growth rate. As discussed in Galbraith et al. (2010), this behavior is common in current model formulations, particularly ones where only the impacts of iron concentration on growth rates are modeled. In fact, observational studies such as those of Hiscock et al. (2008) show that quantum yield and chlorophyll to carbon ratio also increase under iron fertilization. As noted by Galbraith et al. (2010) only more detailed observational studies that parse out different phytoplankton physiological responses can properly constrain which models are most correct.

An additional factor that plays a role in how light affects the model response to relief of iron stress is the thickness of the mixed layer during the growing season and its influence on the average irradiation that phytoplankton experience within the mixed layer. As previously noted, our mixed layer depths are in reasonable agreement with observational estimates at three of our four sites, but not at the Southern Ocean site. As Fig. $4 \mathrm{c}$ shows, the summertime mixed layer thickness at our Southern Ocean site is $\sim 25$ to $50 \mathrm{~m}$, where the Dong et al. (2008) Argo float observations give a depth range of $\sim 50$ to $100 \mathrm{~m}$, i.e., 25 to $50 \mathrm{~m}$ deeper. In the 1-D model study of Mongin et al. (2007), the nitrate drawdown in response to iron fertilization was much greater when they reduced the wind stress forcing and their summertime mixed layer shallowed by $\sim 50 \mathrm{~m}$ from the 50 to $100 \mathrm{~m}$ range to less than $25 \mathrm{~m}$. However, even this shallowing was insufficient to cause nitrate to become depleted in response to iron fertilization in their model. While we believe that the principal reason our model is able to deplete nutrients during the growing season is because of the way iron-light colimitation is modeled, the influence of mixed layer depth on the response clearly merits further study.

Although a full discussion of the dynamics of the prototype TOPAZ ecosystem model is beyond the scope of this paper, we do show here a few additional relevant results from the phytoplankton and Si-system response to increased iron supply. Figure 14 shows the response of chlorophyll and the three types of phytoplankton in the model. We see that small phytoplankton respond to additional iron with increased concentration in the 1200x case, but then begin to decrease in the $1200 x-5$ and $1200 x-10$ simulations as nitrate concentrations drop off. Large phytoplankton are able to keep increasing their concentrations with higher iron additions until the $1200 \mathrm{x}-100$ to $1200 \mathrm{x}-1000$ cases by blooming during periods when nitrate is still present, which is earlier in the year in the high latitude sites and in July to September in the Equatorial Pacific, site. The exception to this is the Ross Sea, where the early bloom does not develop due to the deep wintertime mixed layer and low irradiance (Fig. 3d), as a consequence of which large phytoplankton drop off slightly at 1200x-10, and even more so as greater amounts of iron are added and nitrate concentrations get extremely low during the period when light is present. Diazotrophs are not limited by the fixed nitrogen supply and thus continue to increase at all sites as more and more iron is added. Interestingly, phosphate does not become limiting to diazotrophs, or phytoplankton in general, except during the middle of the growing season at the Southern Ocean site (not shown).

The role of silicic acid in the response of the large phytoplankton to iron addition is of considerable interest because of the important role that diatoms play in the blooms that follow iron additions. As shown in the Supplementary Material, the rate of uptake of silicic acid by large phytoplankton is a complex function of a hyperbolic silicic acid limitation term with a half saturation constant of $5 \mathrm{mmol} \mathrm{m}^{-3}$, the minimum of the hyperbolic fixed nitrogen, phosphate, and iron limitation terms, a $\mathrm{Si}: \mathrm{N}$ ratio that varies between 0.2 and 5.0 as a function of the silicic acid limitation term, and a maximum growth rate that itself is a function of the minimum of the fixed nitrogen, phosphate, and silicic acid limitation terms. We show in Fig. 15a to d the model predicted silicic acid concentration, and in Fig. 15e to h, the model predicted Si:N molar uptake ratio by large phytoplankton.

We consider first the silicic acid concentrations shown in Fig. 15a to d. Both the PAPA and Equatorial Pacific sites have very low silicic acid concentrations that get lower and lower with increasing iron additions until large phytoplankton begin to suffer from nitrogen limitation, at which point the silicic acid concentration increases slightly. The Ross Sea site has much higher silicic acid concentrations, but its response to iron addition during the time when photosynthesis can occur is similar, with silicic acid concentrations dropping with additional iron in the $1200 \mathrm{x}$ and $1200 \mathrm{x}-5$ cases, as 

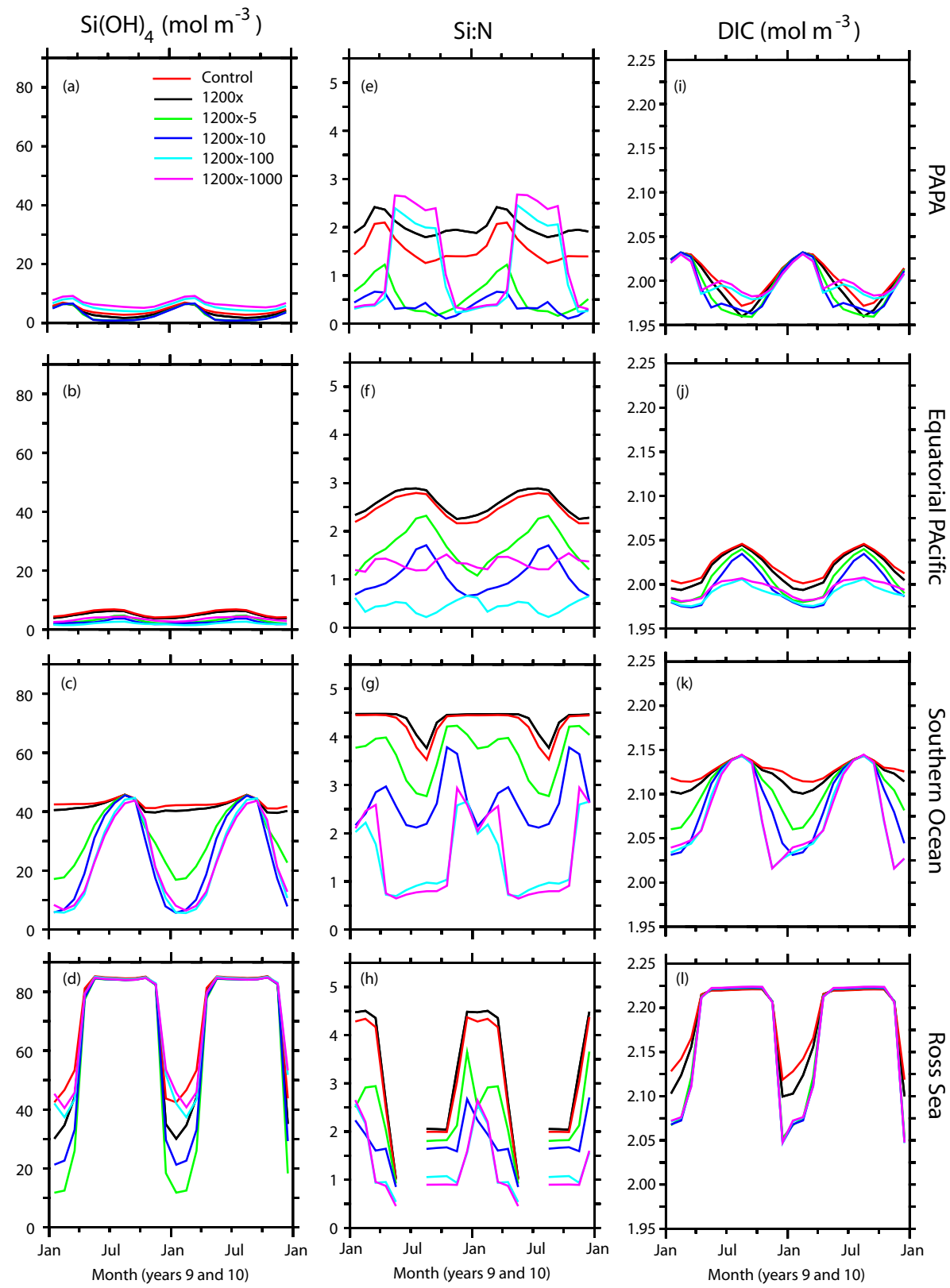

Fig. 15. Mean silicic acid, Si:N, and DIC in the top $10 \mathrm{~m}$ of the four fertilization sites after 10 years of constant fertilization with increasing additions of iron expressed here as a multiple of the standard 1200x scenario.

long as nitrate is present, but then increasing in the $1200 \mathrm{x}-10$ and higher cases as nitrate concentrations become extremely low. As regards the Southern Ocean site, both of the natural fertilization studies at Kerguelen and Crozet show silicic acid dropping to extremely low concentrations during the growth season: $<2 \mathrm{mmol} \mathrm{m}^{-3}$ at Crozet, and $1-2 \mathrm{mmol} \mathrm{m}^{3}$ at Kerguelen (Pollard et al., 2009; and Blain et al., 2007, respectively), by which time they are limiting to diatom growth. Our simulations of silicic acid at the Southern Ocean site get close to but not quite this low (Fig. 15c), nor do our models experience significant silicic acid limitation before nitrate (and phosphate) limitation kick in and prevent silicic acid concentrations from dropping to the point where they become limiting. The Si:N uptake ratios shown in Fig. 15e to $h$ drop at all sites as iron stress is relieved, but then begin to increase again at higher iron concentrations when nitrate becomes limiting. This reduction in the $\mathrm{Si}: \mathrm{N}$ uptake ratio with increased iron supply is one of the factors that prevents the silicic acid from becoming limiting in our model.

As would be expected, surface DIC concentrations initially drop as additional iron is added at all sites (Fig. 15i to 1$)$. However, this effect saturates at $1200 \mathrm{x}-100$ at the two 
Southern Ocean sites, with $1200 x-1000$ being virtually identical. Furthermore, at the equatorial and North Pacific sites, high iron levels lead to increased surface DIC concentrations, possibly reflecting the release of sequestered carbon at depth during wintertime months. Such nonlinear responses to iron fertilization demonstrate the difficulty of scaling the $\mathrm{C}: \mathrm{Fe}$ flux response from small-scale fertilization experiments up to conclusions about global-scale responses to iron fertilization.

\subsubsection{Regional iron stress relief}

We were curious to know how much $\mathrm{CO}_{2}$ would be removed from the atmosphere by our model if iron stress were relieved over large regions such as those given in Column 1 of Table 1. Except in the North Atlantic, and to a lesser extent in the tropics, the results of the set of such simulations summarized in column 3 of Table 1 are quite similar to the KVHISOUTH year-around nutrient depletion simulations shown in column 2 . This result is perhaps a bit surprising given that our patch scale simulations with increasing amounts of iron addition demonstrate that nutrient depletion is possible only during periods of adequate irradiance, which is year around in the Equatorial Pacific, but only about half the year at the other three sites (Fig. 13e, g, and h). Previous work by Marinov (2005) showed that nutrient depletion for 3 summer months in the Southern Ocean south of $30^{\circ} \mathrm{S}$ gave only about twothirds of the $\mathrm{CO}_{2}$ response as a model simulation with year around depletion as in our KVHISOUTH simulations. A more detailed analysis of this interesting result is beyond the scope of this paper, but we note the following: (1) the Marinov (2005) seasonal nutrient depletion sensitivity studies depleted nutrients for only 3 months of the year. Our simulations give nutrient depletion for 6 or more months of the year, which may be sufficient to lift the response above the twothirds level of Marinov's 3-month nutrient depletion period. (2) Except for the North Atlantic case, the global mean reduction in nutrients resulting from each fertilization scenario is very similar in the two sets of simulations shown in Table 1. Possible contributors to this are that the KVHISOUTH scenarios are damped towards observed nutrients outside the nutrient depletion zone, which means that the reduced nutrients in the depletion zone are quickly allowed to grow back in outside the fertilization zone. Also, the 30-day damping time scale of the KVHISOUTH nutrient depletion scenarios is long enough to allow wintertime nutrient concentrations to rise somewhat in response to deep mixing.

\section{Conclusions}

We emphasize the following results from our study:

1. As regards the atmospheric $\mathrm{CO}_{2}$ uptake efficiency (cumulative $\mathrm{CO}_{2}$ uptake divided by cumulative iron addition), our model shows a large response to iron addition at all four of our sites if iron is added for one month per year during the growing season. The atmospheric $\mathrm{CO}_{2}$ uptake efficiency is by far highest at the Ross Sea site, with the Southern Ocean responding at about half the efficiency, and the PAPA and Equatorial Pacific trailing behind. Our results are thus consistent with the findings from the regional nutrient depletion simulations summarized in Table 1. Judging from our own continuous fertilization 1200x scenario, where the Ross Sea efficiency drops drastically, part of the reason Dutkiewicz et al. (2006) found maximum efficiency in the tropics and minimum efficiency in the Southern Ocean region is because they added iron year round, including during the wintertime when the iron can get transported out of the surface without affecting biological export production. Another reason is because their phytoplankton maximum growth rate is more limited by light and less sensitive to iron as discussed in Sect. 4.2.4.

The Ross Sea stands out above all other locations as a place where once atmospheric $\mathrm{CO}_{2}$ is sequestered, it tends to stay sequestered over at least a century time scale (Fig. 8e and f). It also has a high physicalchemical efficiency (Fig. 9d and e) due primarily to the prevention of degassing of excess $\mathrm{CO}_{2}$ through the ice in wintertime (Fig. 10), and the sequestration of much of the excess $\mathrm{CO}_{2}$ in the deep and bottom waters of the ocean (Fig. 6p). Because the Ross Sea site is well south of the biogeochemical divide defined by Marinov et al. (2006), removal of nutrients at this location would have a less deleterious effect on low latitude biological productivity than the Southern Ocean site. On the other hand, the local effects on biological production and the reduction in deep oxygen that then spreads as a tongue into the Pacific Ocean are major undesirable side effects (Fig. 6 and 7), and the issue of verification of the $\mathrm{CO}_{2}$ uptake is at least as serious here as anywhere else.

The Equatorial Pacific and PAPA sites are less efficient as sites for atmospheric $\mathrm{CO}_{2}$ sequestration. The Equatorial Pacific site is highly unfavorable because of the huge negative impact that fertilization at this site may have on the nitrate inventory and thus on global biological productivity.

2. We examined whether additional iron could lead to depletion of nutrients during at least part of the year and found that all the stations can be driven to zero nitrate in the summertime, but only the Equatorial Pacific can be driven to zero mean nitrate year around (Fig. 13). In fact, in the Southern Ocean and Ross Sea, we found that wintertime light limitation causes the nutrient concentration to recover all the way to its normal wintertime maximum even in the highest iron flux case, testifying to the effectiveness of the circulation in returning nutrients to the surface in these two regions. Other model 
studies do not show the same ability to draw down nitrate to zero in the summertime that our model does, which we argued in Sect. 4.2.4 is due primarily to how iron-light colimitation is represented in the models, although the shallow mixed layer in our Southern Ocean simulation (Fig. 4c) may also contribute to our simulation suffering less from light limitation.

3. The back flux of $\mathrm{CO}_{2}$ from the ocean when a realistic atmospheric reservoir is included is substantial (Fig. 11a and Table 6; cf. Gnanadesikan et al., 2003). We strongly recommend that this effect should be taken into account when comparing various $\mathrm{CO}_{2}$ sequestration scenarios with each other, particularly as it is sensitive to the time period of the sequestration. By the 100th year of the 1200x simulation, half of the $\mathrm{CO}_{2}$ that is absorbed by the model with no atmospheric reservoir is lost back to the atmosphere in the model with a realistic atmospheric reservoir. In the case of the $1 \mathrm{x}$ simulation, the escape of sequestered carbon due to this effect is of order $70 \%$ and greater.

4. When the iron added to the ocean follows the same behavior as the background "natural" iron cycle, as in our standard iron fertilization simulations, it is retained in the ocean for a long period of time (Fig. 12) and continues to play a role in boosting the biological productivity (as illustrated by the contrast with the simulation where iron was added then lost, Fig. 11d) and maintaining lower surface nutrient concentrations. By contrast, the physical-chemical efficiency is insensitive to whether the iron is retained or lost (Fig. 11c).

Additional findings which were already covered by the studies of Gnanadesikan et al. (2003) and Matsumoto (2006) include the difficulty of detecting the air-sea flux of $\mathrm{CO}_{2}$ across the air-sea interface, a topic we have not investigated further here as we have nothing new to add; the negative impacts of the fertilization on downstream biological productivity, which we have discussed but not emphasized; and the extraordinarily low efficiency of iron fertilization in removing $\mathrm{CO}_{2}$ from the atmosphere in an iron added and then lost scenario which is intended to mimic the comparable scenario in Gnanadesikan et al. (2003) and Matsumoto (2006). Our model behaves much more like the high efficiency scenarios of macronutrient addition, which Gnanadesikan et al. (2003) claimed was analogous to an iron added and retained scenario.

Based on our model simulations, we would suggest the following as important unknowns that will have a major impact on predictions of the $\mathrm{CO}_{2}$ removal that results from iron fertilization:

1. Processes that determine the physical-chemical efficiency: (a) The locations at which the excess $\mathrm{CO}_{2}$ removed by fertilization is stored in the ocean. This is governed not just by the poorly known remineralization length scale, but also by the subsequent transport of the water masses in which the remineralization occurs. As noted earlier, the Ross Sea site has particularly high fertilization efficiency due in part to the fact that much of the remineralization occurs in waters that subsequently sink into the deep ocean.

(b) The role of a wintertime ice cover in preventing escape of excess $\mathrm{CO}_{2}$ trapped during the summertime growing season.

(c) The return flux of $\mathrm{CO}_{2}$ that occurs in models with a realistic atmospheric reservoir where $\mathrm{CO}_{2}$ drops below where it would otherwise be in response to the iron fertilization. This return flux will be sensitive to the actual concentration of $\mathrm{CO}_{2}$ in the atmosphere and the corresponding oceanic buffer capacity.

2. Processes that determine the biogeochemical response function:

(a) The co-dependence of light and iron and how different formulations of this co-dependence affect the response of ecosystem models to changes in the iron supply. A model comparison study and associated experimental work would be very useful in helping to set up a standard set of simulations that would highlight critical responses of the models and test and improve them.

(b) The long-term fate of the added iron, which has a major impact on the biogeochemical response function (Fig. 11d). This represents an important uncertainty in current models of the iron cycle, which vary substantially in the rates of input and removal of bioavailable iron.

(c) What controls the size of the eastern tropical denitrification regions in models, which is too large in our model as well as in all of the other models we have examined, and which causes the tropics to be the worst location for iron fertilization in this study.

(d) How the air-sea balance of $\mathrm{CO}_{2}$ is associated with changes in the inventory of remineralized nutrients in the ocean. We have had success in analyzing this link for large-scale macronutrient depletion simulations (cf., Marinov et al., 2008; Gnanadesikan and Marinov, 2008), but this has not been done as yet for patch scale iron fertilization simulations. 


\section{Appendix A}

\section{Definition of variables}

We define the flux of tracers such as $\mathrm{Fe}$, organic matter, $\mathrm{CaCO}_{3}$, or $\mathrm{CO}_{2}$ across the air-sea interface or a given depth level, as $f$ in $\mathrm{mol} \mathrm{m}^{2} \mathrm{yr}^{-1}$. We further define the area integral of this flux as

$F=\iint f d x d y$

with units of $\mathrm{mol} \mathrm{yr}^{-1}$, and the cumulative area and time integral as

$\Phi=\int_{0}^{\tau} F d t$

with units of mol. Finally, we define the perturbation of the flux $f$, the area integrated flux $F$, or the area and time integrated flux $\Phi$ as

$\Delta()=()_{\text {fertilization }}-()_{\text {control }}$

Here, the subscript fertilization refers to the patch iron fertilization scenario and control refers to the control scenario with no patch iron fertilization.

\section{Appendix B}

\section{Physical model}

The circulation model used in this study is based on the ocean component of the GFDL CM2.1 global coupled climate model (Griffies et al., 2005b; Gnanadesikan et al., 2006), but with coarser resolution so as to permit long simulations, and a few changes in physical parameterization noted below. The horizontal resolution is $3^{\circ} \times 3^{\circ}$ in the mid-latitudes telescoping to $3^{\circ} \times 2 / 3^{\circ}$ near the equator, thus capturing the critical scales of the equatorial current system. The model has 28 levels in the vertical with a top layer with a nominal thickness of $10 \mathrm{~m}, 9$ layers in the upper $100 \mathrm{~m}$, and bottom topography represented using partial cells so that the bottom is relatively independent of vertical resolution (Pacanowski and Gnanadesikan, 1998). Both the mixing and residual flow associated with mesoscale eddies are parameterized using diffusion coefficients as in Griffies et al. (2005a), with the difference that the maximum thickness diffusion coefficient is increased from $800 \mathrm{~m}^{2} \mathrm{~s}^{-1}$ to $1000 \mathrm{~m}^{2} \mathrm{~s}^{-1}$ (this was done to try to limit excessive Southern Ocean convection). As the model has coarser horizontal resolution, the lateral viscosity is increased so as to resolve the Munk layer in the western boundary.

The model uses an explicit free surface, allowing representation of real freshwater fluxes and eliminating the need for virtual fluxes of carbon dioxide associated with rigidlid models. There is also an explicit mixed layer, the Kprofile parameterization (KPP) of Large et al. (1994) that allows for convective plumes to stir up thermocline water. The overflow parameterization of Campin and Goosse (1999) was included in this run in order to maintain the stability of the Atlantic overturning and to increase the stratification in the Southern Ocean. The vertical diffusion away from the mixed layer varies between $0.15 \mathrm{~cm}^{2} \mathrm{~s}^{-1}$ in the pycnocline and $1.2 \mathrm{~cm}^{2} \mathrm{~s}^{-1}$ in the abyss throughout the World Ocean (in contrast with the CM2.1 models where the pycnocline diffusivity was $0.3 \mathrm{~cm}^{2} \mathrm{~s}^{-1}$ in the polar regions). Sea ice is simulated using the GFDL dynamic/thermodynamic Sea Ice Simulator (SIS) model.

The surface forcing used for the model is the data product of Large and Yeager (2004) prepared for the Coordinated Ocean Reference Experiment (CORE) project (Griffies et al., 2009). The data product used here is a "climatological year" constructed from the CORE product spanning 1958-2004 with sub-monthly variability of 1959 superimposed on it. As such, it fully accounts for seasonal variations, and does not account for interannual variability. The forcing has realistic $6 \mathrm{~h}$ variability in wind speeds, air temperature, relative humidity and atmospheric pressure (thus permitting computation using bulk formulae of sensible and latent heat fluxes and wind stress), realistic daily variability in radiative fluxes, and realistic monthly variability in precipitation, and annualmean runoff. Such formulations do not allow for feedbacks between evaporation and precipitation, as atmospheric relative humidity and temperature are prescribed. Thus, it is necessary to weakly force (restore) surface salinities towards observations to prevent the thermohaline circulation from collapsing. A restoring time scale corresponding to 146 days over the top $10 \mathrm{~m}$ is used for the salinity, with the required corrections being applied as a surface freshwater flux.

\section{Supplementary material related to this article is available online at: http://www.biogeosciences.net/7/3593/2010/ bg-7-3593-2010-supplement.pdf.}

Acknowledgements. JLS, RDS, and MRH acknowledge support from DOE grant DE-FG02-00ER63009 and by the Carbon Mitigation Initiative supported by BP and Ford Motor Company. Early versions of this paper were written during delightful sabbatical visits to Niki Gruber at ETH in Zurich and Nadia Pinardi at the INGV in Bologna. Comments by Xin Jin were very helpful in clarifying our analysis of the fertilization efficiency. We greatly appreciate comments by S. Henson, K. Rodgers, and M. Westley as well the excellent reviews of A. Oschlies and S. Blaine and comments by A. Tagliabue, all of which helped to improve the paper.

Edited by: J. Middelburg 


\section{References}

Abell, J., Emerson, S., and Renaud, P.: Distributions of TOP, TON and TOC in the North Pacific subtropical gyre: Implications for nutrient supply in the surface ocean and remineralization in the upper thermocline, J. Mar. Res., 58, 203-222, 2000.

Anderson, R. F., Ali, S., Bratdmiller, L. I., Nielsen, S. H. H., Fleisher, M. Q., Anderson, B. E., and Burckle, L. H.: Winddriven upwelling in the Southern Ocean and the deglacial rise in atmospheric $\mathrm{CO}_{2}$, Science, 323, 1443-1448, 2009.

Archer, D. E., Eshel, G., Winguth, A., Broecker, W., Pierreumbert, R., Tobis, M., and Jacob, R.: Atmospheric $\mathrm{pCO}_{2}$ sensitivity to the biological pump in the ocean, Global Biogeochem. Cy., 14, 1219-1230, 2000.

Arrigo, K. and Tagliabue, A.: Iron in the Ross Sea: 2. Impact of discrete iron addition strategies, J .Geophys. Res, 110, C03010, doi:10.1029/2004JC002568, 2005.

Aumont, O. and Bopp, L.: Globalizing results from ocean in situ iron fertilization studies, Global Biogeochem. Cy., 20, GB2017, doi:2010.1029/2005GB002591, 2006.

Aumont, O., Maier-Reimer, E., Blain, S., and Monfray, P.: An ecosystem model of the global ocean including $\mathrm{Fe}$, Si, P colimitations, Global Biogeochem. Cy., 17(2), 1060, doi:10.129/2001GB001745, 2003.

Bakker, D. C. E., Neilsdóttir, M. C., Morris, P. J., Venables, H. J., and Watson, A. J.: The island effect and biological carbon uptake for the subatarctic Crozet Archipelago, Deep-Sea Res. Pt. II, 54, 2174-2190, 2007.

Bishop, J. K. B., Wood, T. J., Davis, R. E., and Sherman, J. T.: Robotic observations of enhanced carbon biomass and export at $55^{\circ} \mathrm{S}$ during SOFeX, Science, 304, 417-420, 2004.

Blain, S., Quéguiner, B., Armand, L., Belviso, S., Bombled, B., Bopp, L., Bowie, A., Brunet, C., Brussaard, C., Carlotti, F., Christaki, U., Corbiere, A., Durand, I., Ebersbach, F., Fuda, J.L., Garcia, N., Gerringa, L., Griffiths, B., Guigue, C., Guillerm, C., Jacquet, S., Jeandel, C., Laan, P., Lefevre, D., Monaco, C. L., Malits, A., Mosseri, J., Obernosterer, I., Park, Y.-H., Picheral, M., Pondaven, P., Remenyi, T., Sandroni, V., Sarthou, G., Savoye, N., Scouarnec, L., Souhaut, M., Thuiller, D., Timmermans, K., Trull, T., Uitz, J., Beek, P. v., Veldhuis, M., Vincent, D., Viollier, E., Vong, L., and Wagener, T.: Effect of natural iron fertilization on carbon sequestration in the Southern Ocean, Nature, 446, 1070-1075, 2007.

Bopp, L., Kohfeld, K. E., and Quéré, C. L.: Dust impact on marine biota and atmospheric $\mathrm{CO}_{2}$ during glacial periods, Paleoceanogr., 18, 1046, doi:10.1029/2002PA000810, 2003.

Boyd, P. W., T. Jickells, C. S. Law, S. Blain, E. A. Boyle, K. O. Buesseler, K. H. Coale, J. J. Cullen, H. J. W. de Baar, M. Follows, M. Harvey, C. Lancelot, M. Levasseur, N. P. J. Owens, R. Pollard, R. B. Rivkin, J. Sarmiento, V. Schoemann, V. Smetacek, S. Takeda, A. Tsuda, S. Turner, A. J. Watson: Mesoscale iron enrichment experiments 1993-2005: Synthesis and future directions, Science, 315, 612-617, 2007.

Boyd, P. W., Law, C. S., Wong, C. S., Nojiri, Y., Tsuda, A., Levasseur, M., Takeda, S., Rivkin, R., Harrison, P. J., Strzepek, R., Gower, J., McKay, R. M., Abraham, E., Arychuk, M., BarwellClarke, J., Crawford, W., Crawford, D., Hale, M., Harada, K., Johnson, K., Kiyosawa, H., Kudo, I., Marchetti, A., Miller, W., Needoba, J., Nishioka, J., Ogawa, H., Page, J., Robert, M., Saito, H., Sastri, A., Sherry, N., Soutar, T., Sutherland, N., Taira, Y.,
Whitney, F., Wong, S. K. E., and Yoshimura, T.: The decline and fate of an iron-induced subarctic phytoplankton bloom, Nature, 428, 549-553, 2004.

Boyd, P. W., Strzepek, R., Takeda, S., Jackson, G., C.S., W., McKay, R. M., Law, C., Kiyosawa, H., Saito, H., Sherry, N. J., K., Gower, J., and Ramaiah, N.: The evolution and termination of an iron-induced mesoscale bloom in the northeast subarctic Pacific, Limnol. Oceanogr., 50, 1872-1886, 2005.

Boyd, P. W., Watson, A. J., Law, C. S., Abraham, E. R., Trull, T., Murdoch, R., Bakker, D. C. E., Bowie, A. R., Buesseler, K. O., Chang, H., Charette, M., Croot, P., Downing, K., Frew, R., Gall, M., Hadfield, M., Hall, J., Harvey, M., Jameson, G., LaRoche, J., Liddicoat, M., Ling, R., Maldonado, M. T., McKay, R. M., Nodder, S., Pickmere, S., Pridmore, R., Rintoul, S., Safi, K., Sutton, P., Strzepek, R., Tanneberger, K., Turner, S., Waite, A., and Zeldis, J.: A mesoscale phytoplankton bloom in the polar Southern Ocean stimulated by iron fertilization, Nature, 407, 695-702, 2000.

Buesseler, K. O., Andrews, J. E., Pike, S. M., and Charette, M. A.: The effects of iron fertilization on carbon sequestration in the Southern Ocean, Science, 304, 414-417, 2004.

Buesseler, K. O. and Boyd, P. W.: Will ocean fertilization work?, Science, 300, 67-68, 2003.

Buesseler, K. O., Doney, S. C., Karl, D. M., Boyd, P. W., Caldeira, K., Chai, F., Coale, K. H., de Baar, H. J. W., Falkowski, P. G., Johnson, K. S., Lampitt, R. S., Michaels, A. F., Naqvi, S. W. A., Smetacek, V., Takeda, S., and Watson, A. J.: Ocean iron fertilization-moving forward in a sea of uncertainty, Science, 319, 162, 2008.

Campin, J. M. and Goosse, H.: Parameterization of density-driven downsloping flow for a coarse-resolution model in z-coordinate, Tellus, 51A, 412-430, 1999.

Chever, F., Sarthou, G., Bucciarelli, E., Blain, S., and Bowie, A. R.: An iron budget during the natural iron fertilisation experiment KEOPS (Kerguelen Islands, Southern Ocean), Biogeosciences, 7, 455-468, doi:10.5194/bg-7-455-2010, 2010.

Chisholm, S. W., Falkowski, P. G., and Cullen, J. J.: Dis-crediting ocean fertilization, Science, 294, 309-310, 2001.

Coale, K. H., Johnson, K. S., Chavez, F. P., Buesseler, K. O., Barber, R. T., Brzezinski, M. A., Cochlan, W. P., Millero, F. J., Falkowski, P. G., Bauer, J. E., Wanninkhof, R. H., Kudela, R. M., Altabet, M. A., Hales, B. E., Takahashi, T., Landry, M. R., Bidigare, R. R., Wang, X., Chase, Z., Strutton, P. G., Friederich, G. E., Gorbunov, M. Y., Lance, V. P., Hilting, A. K., Hiscock, M. R., Demarest, M., Hiscock, W. T., Sullivan, K. F., Tanner, S. J., Gordon, R. M., Hunter, C. N., Elrod, V. A., Fitzwater, S. E., Jones, J. L., Tozzi, S., Koblizek, M., Roberts, A. E., Herndon, J., Brewster, J., Ladizinsky, N., Smith, G., Cooper, D., Timothy, D., Brown, S. L., Selph, K. E., Sheridan, C. C., Twining, B. S., and Johnson, Z. I.: Southern Ocean iron enrichment experiment: carbon cycling in high- and low-Si water, Science, 304, 408-414, 2004.

Coale, K. H., Johnson, K. S., Fitzwater, S. E., Gordon, R. M., Tanner, S., Chavez, F. P., Ferioli, L., Sakamoto, C., Rogers, P., Millero, F., Steinberg, P., Nightingale, P., Cooper, D., Cochlan, W. P., Landry, M. R., Constantinou, J., Rollwagen, G., Trasvina, A., and Kudela, R.: A massive phytoplankton bloom induced by an ecosystem-scale iron fertilization experiment in the equatorial Pacific Ocean, Nature, 383, 495-501, 1996. 
Cochlan, W. P., Bronk, D. A., and Coale, K. H.: Trace metals and nitrogenous nutrition of Antarctic phytoplankton: experimental observations in the Ross Sea, Deep-Sea Res. Pt. II, 49, 33653390, 2002.

de Baar, H. J. W., Boyd, P. W., Coale, K. H., Landry, M. R., Tsuda, A., Assmy, P., Bakker, D. C. E., Bozek, Y., Barber, R. T., Brzezinski, M. A., Buesseler, K. O., Boyé, M., Croot, P. L., Gervais, F., Gorbunov, M. Y., Harrison, P. J., Hiscock, W. T., Laan, P., Lancelot, C., Law, C. S., Levasseur, M., Marchetti, A., Millero, F. J., Nishioka, J., Nojiri, Y., van Oijen, T., Riebesell, U., Rijkenberg, M. J. A., Saito, H., Takeda, S., Timmrmans, K. R., Veldhuis, M. J. W., Waite, A. M., and Wong, C. S.: Synthesis of iron fertilization experiments: From the iron age in the Age of Elightenment, J. Geophys. Res., 110, C09S16, doi:10.1029/2004JC002601, 2005.

de Boyer Montégut, C., Madec, G., Fischer, A., Lazar, A., and Iudicone, D.: Mixed layer depth over the global ocean: An examination of profile data and a profile-based climatology, J. Geophys. Res, 109, C12003, doi:10.1029/2004JC002378, 2004.

Dong, S., Sprintall, J., Gille, S., and Talley, L.: Southern Ocean mixed-layer depth from Argo float profiles, J. Geophys. Res., 113, C06013, doi:10.1029/2006JC004051, 2008.

Dunne, J., Armstrong, R., Gnanadesikan, A., and Sarmiento, J.: Empirical and mechanistic models for the particle export ratio, Global Biogeochem. Cy., 19, GB4026, doi:4010.1029/2004GB002390, 2005.

Dunne, J. P., Armstrong, R. A., Gnanadesikan, A. and Sarmiento, J. L.: Ocean biogeochemical variability over the last half century: results from a coupled ocean biogeochemical general circulation model, Eos Trans. AGU, 87(36), Ocean Sci. Meet. Suppl., Abstract OS43A-02, 2006.

Dutkiewicz, S., Follows, M. J., Heimbach, P., and Marshall, J.: Controls on ocean productivity and air-sea carbon flux: An adjoint model sensitivity study, Geophys. Res. Lett., 33, L02603, doi:10.1029/2005GL024987, 2006.

Dutkiewicz, S., Follows, M. J., and Parekh, P.: Interactions of the iron and phosphorus cycles: A threedimensional model study, Global Biogeochem. Cy., 19, GB1021, doi:10.1029/2004GB002342, 2005.

Frost, B. W. and Franzen, N. C.: Grazing and iron limitation in the control of phytoplankton stock and nutrient concentration: a chemostat analogue of the Pacific equatorial upwelling zone, Mar. Ecol.-Prog. Ser., 83, 291-303, 1992.

Fung, I., Meyn, S., Tegen, I., Doney, S., John, J., and Bishop, J.: Iron supply and demand in the upper ocean, Global Biogeochem. Cy., 14, 281-295, 2000.

Galbraith, E. D., Gnanadesikan, A., Dunne, J. P., and Hiscock, M. R.: Regional impacts of iron-light colimitation in a global biogeochemical model, Biogeosciences, 7, 1043-1064, doi:10.5194/bg-7-1043-2010, 2010.

Gall, M. P., Boyd, P. W., Hall, J., Safi, K. A., and Chang, H.: Phytoplankton processes. Part 1: Community structure during the Southern Ocean Iron RElease Experiment (SOIREE), Deep-Sea Res. Pt. II, 48, 2551-2570, 2001.

Garcia, H. E., Locarnini, R. A., Boyer, T. P., and Antonov, J. I.: World Ocean Atlas 2005, Volume 4: Nutrients (phosphate, nitrate, silicate), in: NOAA Atlas NESDIS 64, edited by: Levitus, S., U.S. Government Printing Office, Washington, D. C., 396 pp., 2006.
Geider, R. J., MacIntyre, H. L., and Kana, T. M.: A dynamic model of phytoplankton growth and acclimation: Responses of the balanced growth rate and chlrophyll $a$ : carbon ratio to light, nutrient-limitation and temperature, Mar. Ecol. Prog. Ser., 148, 187-200, 1997.

Gervais, F., Riebesell, U., and Gorbunov, M. Y.: Changes in primary productivity and chlorophyll a in response to iron fertlization in the Southern Polar Frontal Zone, Limnol. Oceanogr., 47, 1324 1335, 2002.

Ginoux, P., Chin, M., Tegen, I., Prospero, J. M., Holben, B., Dubovik, O., and Lin, S. J.: Sources and distributions of dust aerosols simulated with the GOCART model, J. Geophys. Res., 106, 20255-20273, 2001.

Gnanadesikan, A., Dixon, K. W., Griffies, S. M., et al.: GFDL's CM2 global coupled climate models, J. Climate, 19, 675-697, 2006.

Gnanadesikan, A. and Marinov, I.: Export is not enough: Nutrient cycling and carbon, Mar. Ecol.-Prog. Ser., 364, 289-294, 2008.

Gnanadesikan, A., Sarmiento, J. L., and Slater, R. D.: Effects of patchy ocean fertilization on atmospheric carbon dioxide and biological production, Global Biogeochem. Cy., 17, doi:10.1029/2002GB001940., 2003.

Gnanadesikan, A., Slater, R. D., Gruber, N., and Sarmiento, J. L.: Oceanic vertical exchange and new production: a comparison between models and observations, Deep-Sea Res. Pt. II, 49, 363 401, 2002.

Griffies, S. M., Biastoch, A., Böning, C., Bryan, F., Danabasoglu, G., Chassignet, E. P., England, M. H., Gerdes, R., Haak, H., Hallberg, R. W., Hazeleger, W., Jungclaus, J., Large, W. G., Madec, G., Pirani, A., Samuels, B. L., Scheinert, M., Gupta, A. S., Severijns, C. A., Simmons, H. L., Treguier, A. M., Winton, M., Yeager, S., and Yin, J.: Coordinated Ocean-ice Reference Experiments (COREs), Ocean Model., 26, 1-46, 2009.

Griffies, S. M., Gnanadesikan, A., Dixon, K. W., Dunne, J. P., Gerdes, R., Harrison, M. J., Rosati, A., Russell, J. L., Samuels, B. L., Spelman, M. J., Winton, M., and Zhang, R.: Formulation of an ocean model for global climate simulations, Ocean Sci., 1, 45-79, doi:10.5194/os-1-45-2005, 2005a.

Griffies, S. M., Harrison, M. J., Pacanowski, R. C., and Rosati, A.: A technical guide to MOM4, GFDL Ocean Group Technical Report No. 5, NOAA/Geophysical Fluid Dynamics Laboratory, Princeton, 2005b.

Hiscock, M. R., Lance, V. P., Apprill, A, Bidigare, R. R, Johnson, Z. I., Mitchell, B. G. Smith, W. O., and Barber, R. T.: Photosynthetic maximum quantum yield increases are an essential component of the Southern Ocean phytoplankton response to iron Proc. Natl Acad. Sci. USA, 105, 4775-4780, 2008.

Hoffmann, L. J., Peeken, I., Lochte, K., Assmy, P., and Veldhuis, M.: Different reactions of Southern ocean phytoplankton size classes to iron fertilization, Limnol. Oceanogr., 51, 1217-1229, 2006.

Jin, X. and Gruber, N.: Offsetting the radiative benefit of ocean iron fertilization by enahncing $\mathrm{N}_{2} \mathrm{O}$ emissions, Geophys. Res. Lett., 30, 2249, doi:10.1029/2003GL018458, 2003.

Jin, X., Gruber, N., Frenzel, H., Doney, S. C., and McWilliams, J. C.: The impact on atmospheric $\mathrm{CO}_{2}$ of iron fertilization induced changes in the ocean's biological pump, Biogeosciences, 5, 385406, doi:10.5194/bg-5-385-2008, 2008.

Johnson, K. S., Gordon, R. M., and Coale, K. H.: What controls 
dissolved iron concentrations in the world ocean?, Mar. Chem., 57, 137-161, 1997.

Joos, F., Sarmiento, J. L., and Siegenthaler, U.: Estimates of the effect of Southern Ocean iron fertilization on atmospheric $\mathrm{CO}_{2}$ concentrations, Nature, 349, 772-774, 1991.

Jouandet, M. P., Blain, S., Metzl, N., Brunet, C., Trull, T. W., and Obernosterer, I.: A seasonal carbon budget for a naturally iron-fertilized bloom over the Kerguelen Plateau in the Southern Ocean, Deep-Sea Res. Pt. II, 55, 856-867, 2008.

Knox, F. and McElroy, M.: Changes in atmospheric $\mathrm{CO}_{2}$, influence of marine biota at high latitudes, J. Geophys. Res., 89, 46294637, 1984.

Kurz, K. D. and Maier-Reimer, E.: Iron fertilization of the Austral Ocean-the Hamburg model assessment, Global Biogeochem. Cy., 7, 229-244, 1993.

Lance, V. P., Hiscock, M. R., Hilting, A. K., Stuebe, D. A., Bidigare, R. R., Smith Jr., W. O., and Barber, R. T.: Primary productivity, diferential size fraction and pigment composition responses in two Southern Ocean in situ iron enrichments, Deep-Sea Res. Pt. I, 54, 747-773, 2007.

Landry, M. R.: Integrating classical and microbial food web concepts: evolving views from the open-ocean tropical Pacific, Hydrobiologia, 480, 29-39, 2002.

Large, W. G., McWilliams, J. C., and Doney, S. C.: Oceanic vertical mixing: A review and a model with a nonlocal boundary layer, Rev. Geophys., 32, 363-403, 1994.

Large, W. G. and Yeager, S. G.: Diurnal to decadal global forcing for ocean and sea-ice models: The data sets and flux climatologies. Tech. Rep. NCAR/TN-460_STR, National Center for Atmospheric Research, Boulder, CO., National Center for Atmospheric Research, Boulder, CO, 2004.

Law, C. S., Crawford, W. R., Smith, M. J., Boyd, P. W., Wong, C. S., Nojiri, Y., Robert, M., Abraham, E. R., Johnson, W. K., Forsland, V., and Arychuk, M.: Patch evolution and the biogeochemical impact of entrainment during a mesoscale iron enrichment in the subarctic Pacific, Deep-Sea Res. Pt. II, 53, 2012-2033, 2006.

Letelier, R. M. and Karl, D. M.: Trichodesmium spp. physiology and nutrient fluxes in the North Pacific subtropical gyre, Aquat. Microb. Ecol., 15, 265-276, 1998.

Marchetti, A., Sherry, N. D., Kiyosawa, H., Tsuda, A., and Harrison, P. J.: Phytoplankton processes during a mesoscale iron enrichment in the NE subarctic Pacific: Part I- Biomass and assemblage, Deep-Sea Res. Pt. II, 53, 2095-2113, 2006.

Marinov, I.: Controls on the air-sea balance of carbon dioxide. $\mathrm{PhD}$ thesis, Program in Atmospheric and Oceanic Sciences, Princeton University, Princeton, 224 pp., 2005.

Marinov, I., Follows, M., Gnanadesikan, A., Sarmiento, J. L., and Slater, R. D.: How does ocean biology affect atmospheric $\mathrm{pCO}_{2}$, Theory and models, J. Geophys. Res., 113, C07032, doi:10.1029/2007JC004598, 2008.

Marinov, I., Gnanadesikan, A., Toggweiler, J. R., and Sarmiento, J. L.: The Southern Ocean biogeochemical divide, Nature, 441, 964-967, 2006.

Martin, J. H.: Glacial-interglacial $\mathrm{CO}_{2}$ change: the iron hypothesis, Paleoceanogr., 5, 1-13, 1990.

Martin, J. H., Coale, K. H., Johnson, K. S., Fitzwater, S. E., Gordon, R. M., Tanner, S. J., Hunter, C. N., Elrod, V. A., Nowicki, J. L., Coley, T. L., Barber, R. T., Lindley, S., Watson, A. J., Vanscoy, K., Law, C. S., Liddicoat, M. I., Ling, R., Stanton, T., Stockel, J.,
Collins, C., Anderson, A., Bidigare, R., Ondrusek, M., Latasa, M., Millero, F. J., Lee, K., Yao, W., Zhang, J. Z., Friederich, G., Sakamoto, C., Chavez, F., Buck, K., Kolber, Z., Greene, R., Falkowski, P., Chisholm, S. W., Hoge, F., Swift, R., Yungel, J., Turner, S., Nightingale, P., Hatton, A., Liss, P., and Tindale, N. W.: Testing the iron hypothesis in ecosystems of the equatorial Pacific Ocean, Nature, 371, 123-129, 1994.

Martin, J. H., Fitzwater, S. E., and Gordon, R. M.: Iron deficiency limits phytoplankton growth in Antarctic waters, Global Biogeochem. Cy., 4, 5-12, 1990a.

Martin, J. H., Gordon, R. M., and Fitzwater, S. E.: Iron in Antarctic waters, Nature, 345, 156-158, 1990 b.

Martin, J. H., Knauer, G. A., Karl, D. M., and Broenkow, W. W.: VERTEX: Carbon cycling in the northeast Pacific, Deep-Sea Res., 34, 267-285, 1987.

Matear, R. and Elliott, B.: Enhancement of oceanic uptake of anthropogenic carbon by macronutrient fertilization, J. Geophys. Res., 109, C04001, doi:1029/2000JC000321, 2004.

Matsumoto, K.: Model simulations of carbon sequestration in the northwest Pacific by patch fertilization, J. Oceanogr., 62, 887902, 2006.

Middelburg, J. J., Soetaert, K., Herman, P. M. J., and Heip, C. H. R.: Denitrification in marine sediments: A model study, Global Biogeochem. Cy., 10, 661-673, 1996.

Mongin, M., Nelson, D. M., Pondaven, P., and Tréguer, P.: Potential phytoplankton response to iron and stratification changes in the Southern Ocean based on a flexible-composition phytoplankton model, Global Biogeochem. Cy., 21, GB4020, doi:4010.1029/2007GB002972, 2007.

Moore, J. K. and Doney, S. C.: Iron availability limits the ocean nitrogen inventory stabilizing feedbacks between marine denitrification and nitrogen fixation, Global Biogeochem. Cy., 21, GB2001, doi:10.1029/2006GB002762, 2007.

Moore, J. K., Doney, S. C., Glover, D. M., and Fung, I. Y.: Iron cycling and nutrient-limitation patterns in surface waters of the World Ocean, Deep-Sea Res. Pt. II, 49, 463-507, 2002a.

Moore, J. K., Doney, S. C., Kleypas, J. A., Glover, D. M., and Fung, I. Y.: An intermediate complexity marine ecosystem model for the global domain, Deep-Sea Res. Pt. II, 49, 463-507, 2002 b.

Orr, J. C. and Sarmiento, J. L.: Potential of marine macroalgae as a sink for $\mathrm{CO}_{2}$ : constraints from a 3-D general circulation model of the global ocean., Water Air Soil Poll., 64, 405-421, 1992.

Oschlies, A.: Impact of atmospheric and terrestrial $\mathrm{CO}_{2}$ feedbacks on fertilization-induced marine carbon uptake, Biogeosciences, 6, 1603-1613, doi:10.5194/bg-6-1603-2009, 2009

Pacanowski, R. C. and Gnanadesikan, A.: Transient response in a z-level ocean model with bottom topography resolved using the method of partial cells, Mon. Weather Rev., 104, 3248-3270, 1998.

Peng, T. H. and Broecker, W. S.: Dynamic limitations on the Antarctic iron fertilization strategy: Nature, 349, 227-229, 1991.

Pollard, R. T., Salter, I., Sanders, R. J., Lucas, M. I., Moore, C. M., Mills, R. A., Statham, P. J., Allen, J. T., Baker, A. R., Bakker, D. C. E., Charette, M. A., Fielding, S., Fones, G. R., French, M., Hickman, A. E., Holland, R. J., Hughes, J. A., Jickells, T. D., Lampitt, R. S., Morris, P. J., Nédélec, F. H. N., M, Planquette, H., Popova, E. E., Poulton, A. J., Read, J. F. S., S, Smith, T., Stinchcombe, M., Taylor, S., Thomalla, S., Venables, H. J., Williamson, R., and Zubkov, M. V.: Southern Ocean deep-water 
carbon export enhanced by natural iron fertilization, Nature, 457, 577-580, 2009.

Sarmiento, J. L. and Gruber, N.: Ocean Biogeochemical Dynamics, Princeton University Press, Princeton, 2006.

Sarmiento, J. L. and Orr, J. C.: Three-dimensional simulations of the impact of Southern Ocean nutrient depletion on atmospheric $\mathrm{CO}_{2}$ and ocean chemistry, Limnol. Oceanogr., 36, 1928-1950, 1991.

Sarmiento, J. L. and Toggweiler, J. R.: A new model for the role of the oceans in determining atmospheric $\mathrm{pCO}_{2}$, Nature, 308, 621-624, 1984.

Schiermeier, Q.: Climate change: The oresmen, Nature, 421, 109110, 2003.

Schneider, B., Bopp, L., Gehlen, M., Segschneider, J., Frlicher, T. L., Cadule, P., Friedlingstein, P., Doney, S. C., Behrenfeld, M. J., and Joos, F.: Climate-induced interannual variability of marine primary and export production in three global coupled climate carbon cycle models, Biogeosciences, 5, 597-614, doi:10.5194/bg-5-597-2008, 2008.

Sharada, M. K., Yajnik, K. S., and Swathi, P. S.: Evaluation of six relations of the kinetics of uptake by phytoplankton in multinutrient environment using JGOFS experimental results, DeepSea Res. Pt. II, 52, 1892-1909, 2005.

Shepherd, J.: Geoengineering the climate: Science, governance and uncertainty, RS Policy document 10/09, The Royal Society, London, 1-82 pp., 2009.

Siegenthaler, U. and Wenk, T.: Rapid atmospheric $\mathrm{CO}_{2}$ variations and ocean circulation, Nature, 308, 624-626, 1984.

Sigman, D. M. and Boyle, E. A.: Glacial/interglacial variations in atmospheric carbon dioxide, Nature, 407, 859-869, 2000.
Strong, A., Chisholm, S. Miller, C., and Cullen, J.: Ocean fertilization: time to move on, Nature, 461, 347-348, 2009.

Sunda, W. G.: Bioavailability and bioaccumulation of iron in the sea, in: The Biogeochemistry of Iron in Seawater, edited by: Turner, D. R. and Hunter, K. A., John Wiley \& Sons, Ltd., Chichester, 41-84, 2001.

Sunda, W. G. and Huntsman, S. A.: Interrelated influence of iron, light and cell size on marine phytoplankton growth, Nature, 390, 389-392, 1997.

Tagliabue, A. and Arrigo, K. R.: Processes governing the supply of iron to phytoplankton in stratified seas, J. Geophys. Res., 111, C06019, doi:10.1029/2005JC003363, 2006.

Tagliabue, A., Bopp, L., and Aumont, O.: Ocean biogeochemistry exhibits contrasting responses to a large scale reduction in dust deposition, Biogeosciences, 5, 11-24, doi:10.5194/bg-5-112008, 2008.

Takeda, S. and Tsuda, A.: An in situ iron-enrichment experiment in the western subarctic Pacific (SEEDS): Introduction and summary, Progr. Oceanogr., 64, 95-109, 2005.

Tsuda, A., Takeda, S., Saito, H., Nishioka, J., Nojiri, Y., Kudo, I., Kiyosawa, H., Shiomoto, A., Imai, K., Ono, T., Shimamoto, A., Tsumune, D., Yoshimura, T., Aono, T., Hinuma, A., Kinugasa, M., Suzuki, K., Sohrin, Y., Noiri, Y., Tani, H., Deguchi, Y., Tsurushima, N., Ogawa, H., Fukami, K., Kuma, K., and Saino, T.: A mesoscale iron enrichment in the western Subarctic Pacific induces a large centric diatom bloom, Science, 300, 958-961, 2003.

Zeebe, R. E. and Archer, D.: Feasibility of ocean fertilization and its impacts on future atmospheric $\mathrm{CO}_{2}$ levels, Geophys. Res. Lett., 32, L09703, doi:09710.01029/02005GL022449, 2005. 